\title{
COVID-19: potential therapeutics for pediatric patients
}

\author{
Nour K. Younis $^{1} \cdot$ Rana O. Zareef $^{1} \cdot$ Ghina Fakhri $^{2} \cdot$ Fadi Bitar $^{1,2} \cdot$ Ali H. Eid $^{3,4}\left(\right.$ D $\cdot$ Mariam Arabi $^{1,2}$
}

Received: 26 April 2021 / Revised: 6 July 2021 / Accepted: 26 July 2021 / Published online: 30 August 2021

(c) The Author(s) 2021

\begin{abstract}
The global spread of COVID-19 has imparted significant economic, medical, and social burdens. Like adults, children are affected by this pandemic. However, milder clinical symptoms are often experienced by them. Only a minimal proportion of the affected patients may develop severe and complicated COVID-19. Supportive treatment is recommended in all patients. Antiviral and immunomodulatory medications are spared for hospitalized children with respiratory distress or severe to critical disease. Up till now, remdesivir is the only USFDA-approved anti-COVID-19 medication indicated in the majority of symptomatic patients with moderate to severe disease. Dexamethasone is solely recommended in patients with respiratory distress maintained on oxygen or ventilatory support. The use of these medications in pediatric patients is founded on evidence deriving from adult studies. No randomized controlled trials (RCTs) involving pediatric COVID-19 patients have assessed these medications' efficacy and safety, among others. Similarly, three novel monoclonal anti-SARS-CoV-2 spike protein antibodies, bamlanivimab, casirivimab and imdevimab, have been recently authorized by the USFDA. Nonetheless, their efficacy has not been demonstrated by multiple RCTs. In this review, we aim to dissect the various potential therapeutics used in children with COVID-19. We aspire to provide a comprehensive review of the available evidence and display the mechanisms of action and the pharmacokinetic properties of the studied therapeutics. Our review offers an efficient and practical guide for treating children with COVID-19.
\end{abstract}

Keywords COVID-19 $\cdot$ Pediatric patients $\cdot$ SARS-CoV-2 $\cdot$ Therapeutics

$\begin{array}{lll}\begin{array}{ll}\text { Abbreviations } \\ \text { SARS-CoV-2 }\end{array} & \begin{array}{l}\text { Severe acute respiratory syndrome corona- } \\ \text { virus 2 }\end{array} & \begin{array}{l}\text { ARDS } \\ \text { MIS-C }\end{array} \\ \text { COVID-19 } & \begin{array}{l}\text { Coronavirus disease 2019 } \\ \text { RCT }\end{array} & \text { Randomized controlled trials } \\ \text { WHO } & \text { World Health Organization } & \text { CQ } \\ \text { USFDA } & \text { US Food and Drug Administration } & \text { GFR } \\ & & \text { Il1- } \alpha \\ & & \text { TNF- } \alpha\end{array}$

Nour K. Younis and Rana O. Zareef have contributed equally to this manuscript.

\author{
Standard of care \\ Acute respiratory distress syndrome \\ Multisystem inflammatory syndrome in \\ children \\ Chloroquine \\ Hydroxychloroquine \\ Glomerular filtration rate \\ Interleukin 1 alpha \\ Tumor necrosis factor alpha
}

Ali H. Eid

ali.eid@qu.edu.qa

Mariam Arabi

ma81@aub.edu.lb

Nour K. Younis

nky02@mail.aub.edu

Rana O. Zareef

roz01@mail.aub.edu

Ghina Fakhri

gf15@aub.edu.lb

Fadi Bitar

fbitar@aub.edu.lb
1 Faculty of Medicine, American University of Beirut Medical Center, Riad El Solh, 11-0236, Beirut 1107 2020, Lebanon

2 Department of Pediatrics, Division of Pediatric Cardiology, American University of Beirut Medical Center, Riad El Solh, 11-0236, Beirut 1107 2020, Lebanon

3 Department of Basic Medical Sciences, College of Medicine, QU Health, Qatar University, 2713, Doha, Qatar

4 Biomedical and Pharmaceutical Research Unit, QU Health, Qatar University, 2713, Doha, Qatar 


\begin{tabular}{|c|c|}
\hline II-6 & Interleukin 6 \\
\hline IVIG & Intravenous immunoglobulin \\
\hline $\mathrm{RdRp}$ & RNA-dependent RNA polymerase \\
\hline $\mathrm{ICU}$ & Intensive care unit \\
\hline SARS-CoV & $\begin{array}{l}\text { Severe acute respiratory syndrome } \\
\text { coronavirus }\end{array}$ \\
\hline MERS-CoV & $\begin{array}{l}\text { Middle East respiratory syndrome } \\
\text { coronavirus }\end{array}$ \\
\hline $\mathrm{S}$ protein & Spike protein \\
\hline nsp12 & Non-structural protein 12 \\
\hline ExoN & Exoribonuclease \\
\hline LY-CoV555 & Bamlanivimab \\
\hline REGN-CoV2 & Casirivimab/imdevimab \\
\hline EMA & European Medicines Agency \\
\hline NIH & National Institutes of Health \\
\hline EUA & Emergency Use Authorization \\
\hline
\end{tabular}

\section{Introduction}

Toward the end of 2019, a few atypical lower respiratory illness cases were witnessed in Wuhan, China [1-5]. The exact etiology of this viral-like novel respiratory illness remained unclear until the 7th of January 2020. At that time, a novel coronavirus, named severe acute respiratory syndrome coronavirus 2 (SARS-CoV-2), was extracted from patients' respiratory tract samples $[1,2]$. The disease of SARS-CoV-2, namely coronavirus disease 2019 (COVID-19), was later recognized as a global pandemic on the 11th of March, 2020, by the World Health Organization (WHO) [6, 7]. This pandemic has, since, imposed significant morbidity and mortality rates and has led to overwhelmed and weakened medical systems in all nations. As of June 23, 2021, COVID-19 has afflicted more than 178 million individuals and caused 3.88 million deaths worldwide [8].

Since the beginning of the pandemic, an effective treatment for COVID-19 has been sought. Despite the unprecedented race to find a cure, most efforts have been directed toward repurposing well-studied and -recognized medications $[9,10]$. Of these medications, we list azithromycin, dexamethasone, favipiravir, hydroxychloroquine, oseltamivir, remdesivir, and ivermectin [11-14]. Immunomodulators, such as tocilizumab, and anti-HIV medicines, such as lopinavir and ritonavir, have been similarly investigated [11-14]. Additionally, many hospitalized patients with severe and complicated COVID-19 have received convalescent plasma of compatible recovered patients $[11,15-18]$. The role of vitamins and minerals, including vitamin $C$, vitamin $D$, and zinc, in treating and preventing COVID-19 has been additionally examined [19-21].

Despite the above-mentioned numerous attempts and investigations, the US Food and Drug Administration (USFDA) has been very cautious and meticulous in selecting the appropriate treatment for COVID-19. In May 2020, USFDA authorized remdesivir only in patients with severe and critical diseases [22]. Toward the end of August 2020 , the use of remdesivir was approved for all hospitalized patients regardless of the severity of the disease [22]. After that, on October 22 of this year, USFDA has approved the use of remdesivir in all hospitalized patients aged at least 12 years who weigh more than $40 \mathrm{~kg}$ [23]. Nonetheless, supportive measures, geared toward symptom control, have continued to be the core first-line management of COVID-19 in non-hospitalized patients with mild to moderate disease, as discussed below. Hydration and fever control with antipyretics represent the standard of care (SOC) offered to all patients.

This review discusses the studied potential therapeutics that can be used in treating children with COVID-19. It provides a comprehensive and updated review of the current evidence. This review reports the most updated highestquality evidence that derives from American and European multicentered clinical trials and guidelines.

\section{Methods}

This review intends to scrutinize the COVID-19 therapeutics that can be offered to pediatric patients. It aims also to suggest an effective treatment algorithm and discuss the accepted dosages of the potential medications and their side effects. It involves a thorough search of the recently published literature and includes studies published in the databases of Cochrane, Embase, Medline, and PubMed. We searched for the following MeSH terms and keywords: COVID-19, coronavirus disease 2019, therapeutics, therapy, treatment, azithromycin, chloroquine/hydroxychloroquine, dexamethasone, ivermectin, lopinavir/ritonavir, oseltamivir, remdesivir, tocilizumab, vitamin, and minerals. We limited our search to clinical trials, meta-analysis, and systematic reviews. We reviewed all relevant studies and inspected closely for studies involving pediatric patients. Similarly, we examined the international guidelines issued by USFDA and EMA.

\section{Potential therapeutics for children with COVID-19}

Numerous medications have been considered as potential therapeutics for COVID-19 and investigated in pre-clinical and clinical studies. These medicines are well-known and -studied treatments commonly employed in the management of autoimmune diseases and viral, bacterial, and parasitic infections. Because of their well-established antimicrobial and anti-inflammatory properties, clinicians and researchers 
have endorsed the use of these therapeutic options. This use is also supported by the immunomodulatory effects exerted by some of these medicines.

The clinical course of COVID-19 in pediatric patients is mild in almost all cases [24-26]. However, severe and critical illness can affect a minor percentage of infected patients. Serious complications, such as severe pneumonia, acute respiratory distress syndrome (ARDS), multisystem inflammatory syndrome in children (MIS-C), and sepsis, can occur [25, 27-29].

Treatment of COVID-19 pediatric patients entails supportive and symptomatic management. It includes hydration with intravenous and/or oral fluids, fever reduction with antipyretics, and oxygen supplementation. The use of remdesivir and the off-label use of additional antiviral medications and immunomodulators are spared for hospitalized patients with respiratory distress and complicated disease [26, 30].

In April 2020, the American Pediatric Infectious Diseases Society endorsed therapeutic guidance provided by a group of American infectious disease specialists and pharmacists [31]. In this guidance, they recommended adopting a personalized therapeutic plan that depends on the patient's clinical status and medical history. They endorsed the use of remdesivir in children (aged at least 12 years) with severe and critical diseases [31]. Similarly, they suggested using hydroxychloroquine (HCQ) as second-line treatment in this population (children aged 12 years and above) and as firstline treatment in younger children aged 12 years and less. The use of lopinavir and ritonavir was not approved by all the participants. Similarly, they advised against the addition of azithromycin to HCQ, and ribavirin to lopinavir/ritonavir [31].

At the end of September 2020, the Italian Society of Infectious Pediatric Diseases suggested using remdesivir in pediatric patients with severe or critical COVID-19 in whom renal and liver functions are normal [32]. HCQ and lopinavir/ritonavir should be only considered if remdesivir is contraindicated or unavailable. Similarly, immunomodulatory therapies, such as anakinra, dexamethasone, and tocilizumab, should be considered in patients with ARDS, MIS-C, prolonged disease course, or enhanced elevation in inflammatory markers [32].

Furthermore, according to the most recent treatment guideline issued by the Children's Hospital of King's Daughter (CHKD) in southeastern Virginia, supportive care must be offered to all patients [33]. Dexamethasone should be added in patients receiving respiratory support including oxygen and assisted ventilation. Remdesivir, on the other hand, should be reserved for hospitalized COVID-19 patients who are on invasive ventilators. Its use is contraindicated in patients with (1) multiorgan dysfunction, (2) vasopressor support, (3) markedly elevated alanine aminotransferase (ALT), (4) severe renal impairment (GFR $<30 \mathrm{ml} / \mathrm{min}$ and dialysis), or (5) concurrent administration of other antivirals [33]. Tocilizumab and anakinra must be considered when remdesivir is contraindicated or inaccessible. These medications are also indicated in patients at high risk for developing complicated disease reflected by severe worsening of respiratory function despite mechanical ventilation, and markedly elevated inflammatory markers (ferritin, Il-6, LDH, and D-dimer) [33]. They are also indicated in patients with severe MIS-C. Intravenous immunoglobulin (IVIG), aspirin, and anticoagulants are indicated in patients with MIS-C regardless of severity [33].

The use of other therapeutics, including azithromycin, ivermectin, and oseltamivir, among others, has been likely explored [34, 35]. Herein, we provide a review of the latest highest-quality evidence that discusses the anti-COVID-19 properties and the efficacy of the following medications: azithromycin, chloroquine/hydroxychloroquine, dexamethasone, ivermectin, lopinavir/ritonavir, oseltamivir, remdesivir, and tocilizumab. We also describe the therapeutic role of the novel monoclonal anti-SARS-CoV-2 spike protein antibodies recently authorized by the USFDA. The role of vitamin and mineral supplements in treating COVID-19 is equally discussed. This review aims to convey a brief description of the mechanism of action and the pharmacokinetic properties of the aforementioned medications. Due to the lack of randomized controlled trials (RCTs) involving pediatric patients, most of the below evidence is derived from highquality adult RCTs.

\section{Chloroquine/hydroxychloroquine}

\section{Mechanism of action}

The synthetic derivatives of quinine, chloroquine (CQ) and hydroxychloroquine (HCQ), were formerly employed in treating malaria, autoimmune, cutaneous, and rheumatic diseases [36]. Similarly, CQ and HCQ were effective against various bacterial and viral infections including Coxiella burnetii, Tropheryma whipplei, Ebola virus, Hepatitis $C$, and chikungunya [36]. Their clinical uses are derived from their anti-inflammatory, immunomodulatory, and antimicrobial properties. CQ/HCQ inhibits viral entry and intracellular replication (see Fig. 1). They exert their antiviral effects via (1) the inhibition of sialic acid synthesis, (2) the binding to sialic acid and gangliosides, (3) the impairment of viral cellular interaction, and (4) the interference with intracellular pathways that are key for viral replications such as p38 mitogen-activated protein kinase (MAPK) pathway [36]. Similarly, they boost the dendritic cells' activity which, in turn, enhances the activity of cytotoxic $\mathrm{T}$ cells. They are known to attenuate the inflammatory response mounted against pathogens and autoimmune triggers. This effect is achieved via the downregulation of the release of pro-inflammatory 


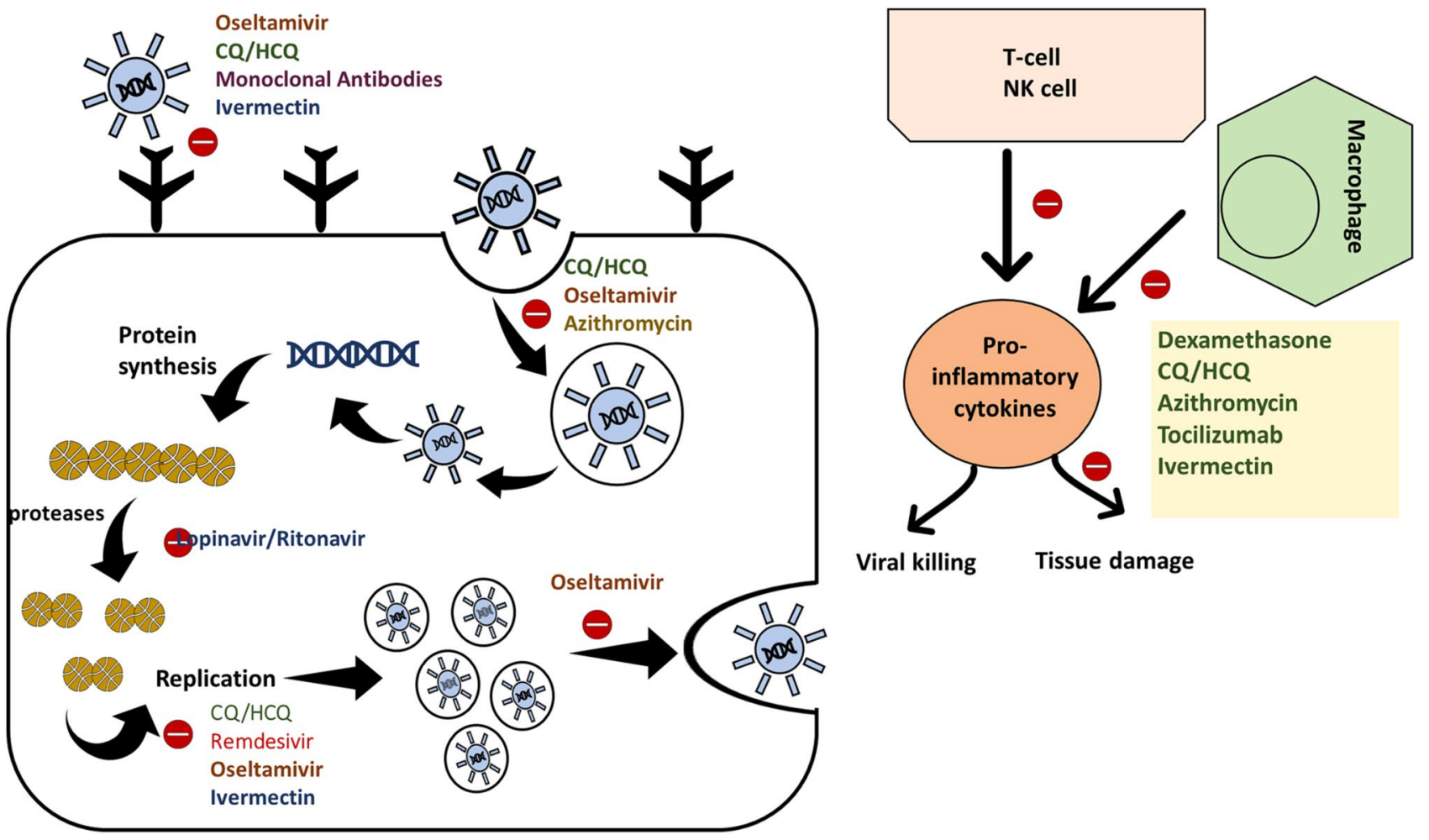

Fig. 1 The potential therapeutics of COVID-19 and their suggested mechanisms of action. Chloroquine/hydroxychloroquine (CQ/HCQ) is known for its anti-inflammatory and antimicrobial effects. They inhibit viral fusion, endocytosis, and intracellular replication. Similarly, they modulate the inflammatory response mounted against the virus by attenuating the excessive uncontrolled release of proinflammatory cytokines. Oseltamivir is a selective inhibitor of the neuraminidase enzymes of the influenza virus. These enzymes are involved in various viral processes including viral entry, replication, packaging, and release. Hence, their use in SARS-CoV-2 infection may thwart the cellular processing of this virus at different levels. Remdesivir is a potent inhibitor of viral replication. It exerts its effect through the selective inhibition of the RNA-dependent RNA polymerase. Remdesivir, unlike CQ/HCQ, oseltamivir, and ivermectin,

cytokines (such as I11- $\alpha$, TNF- $\alpha$, and Il6) that can result in hyperinflammation and tissue destruction [36].

\section{Pharmacology}

The elimination half-life of HCQ is estimated at 40-50 days [37]. The bioavailability of oral CQ and HCQ is estimated at $70-80 \%$. Hence, their use in the oral formulation can achieve adequate therapeutic concentrations in most patients [37]. CQ and HCQ display moderate binding to plasma proteins and have high volumes of distribution [36-38]. No dosage adjustment is indicated in patients with liver and kidney diseases. However, the drugs are metabolized by the liver and excreted in urine and feces [38]. Hence, caution should be applied when treating patients with liver or kidney dysfunction. is a direct inhibitor of RNA-dependent RNA polymerase. CQ/HCQ, oseltamivir, and ivermectin hinder indirectly the replication through a cascade of events. On the contrary, dexamethasone, azithromycin, and tocilizumab are recognized for their anti-inflammatory effects. They control the inflammatory response mounted against the infection and hamper the progression to uncontrolled hyperinflammation and tissue destruction. These medications may alleviate the cytokine storm syndrome that may be associated with severe and complicated SARS-CoV-2 infections. Hence, they attenuate the tissue damage that may accompany viral killing. Similarly, the newly synthesized antiSARS-CoV-2 spike protein antibodies are inhibitors of viral fusion and internalization. Viral endocytosis is also impeded by azithromycin. Moreover, ivermectin seems to inhibit viral uptake and replication as well as pro-inflammatory cytokines production

\section{Clinical evidence}

A retrospective cohort study involving 582 pediatric patients admitted to 82 European hospitals reported that hydroxychloroquine, remdesivir, and lopinavir-ritonavir were the most-used medications [39]. However, up till now, no RCTs have assessed the efficacy of these medications, among others, in treating pediatric COVID-19 patients. The currently available evidence is solely derived from adult-targeted studies.

Based on the latest evidence deriving from high-quality RCTs, hydroxychloroquine has been found non-superior to standard care in the treatment of adult COVID-19 patients [40, 41]. The SOLIDARITY trial, conducted by the WHO, has the largest number of enrolled patients (around 12,000 patients) treated in more than 500 hospitals globally. As per 
the preliminary results of this trial, little or no benefit can be induced by the addition of hydroxychloroquine to the standard care of COVID-19 patients. Similarly, in this study, remdesivir and lopinavir-ritonavir were not associated with a significant improvement in mortality and in-hospital clinical status [40].

Congruently, the RECOVERY collaborative group has assessed the efficacy of hydroxychloroquine and usual care in a cohort of 4716 patients [41]. One thousand five hundred and sixty-one patients were randomly assigned to the hydroxychloroquine-treated group. The rest of the patients were only provided with supportive care. No improvement in 28-day mortality and overall clinical outcomes was caused by the addition of HCQ [41]. Moreover, a higher incidence of mortality and transition to mechanical ventilation was encountered in the HCQ-treated group. A mildly increased incidence of cardiac-related deaths was witnessed in this group as well [41].

The studies mentioned above represent the largest studies with the highest quality of evidence. They are superior to the formerly published observational studies that supported the use of HCQ in treating COVID-19 [36, 42-45]. These former studies are limited by the small number of enrolled patients, the lack of control and randomization, and the known inherent biases of retrospective observational studies. In short, the use of HCQ cannot be warranted based on the currently available data. Hence, further RCTs are needed to elucidate the exact role of HCQ and endorse alternative safe and effective medications.

\section{Dexamethasone}

\section{Mechanism of action}

Dexamethasone is a corticosteroid with potent anti-inflammatory and immunomodulatory activities. It downregulates the immune response mounted against endogenous autoimmune insults, such as auto-antibodies targeted against selfantigens, and exogenous triggers such as SARS-CoV-2. It exerts this effect by inhibiting neutrophils' migration to inflammatory sites, and inducing apoptosis of basophils, eosinophils, lymphocytes, and monocytes [46]. Dexamethasone is also known to inhibit lymphocytes proliferation. Derived from its immunosuppressive effects, the use of dexamethasone is associated with a diminished expression and production of pro-inflammatory cytokines and an increased expression and production of anti-inflammatory cytokines [47-49]. Similarly, dexamethasone is employed in treating numerous pulmonary diseases such as asthma, chronic bronchitis and emphysema [50]. It reduces pulmonary inflammation resulting in improved respiratory functions [50]. Hence, it is postulated that the addition of dexamethasone to standard care is warranted in COVID-19 patients with respiratory distress and severe disease.

\section{Pharmacology}

The half-life of dexamethasone is estimated at 4.1 to $5.4 \mathrm{~h}$ [51]. It has a good oral bioavailability estimated at around $70-80 \%$ [51, 52]. Hence, it can be administered orally or intravenously. Dexamethasone exhibits extensive plasma protein binding and its volume of distribution may be as high as $99 \mathrm{~L}$ [51]. The liver metabolizes it into more watersoluble metabolites excreted by the kidneys [51]. Hence, careful dosing and monitoring of side effects are mandatory when dealing with hepatic and renal diseases.

\section{Clinical evidence}

Owing to its favored anti-inflammatory and respiratory effects, the use of dexamethasone in patients with COVID19 has gained much attention. This use has been examined by several groups of medical clinicians and researchers. On the 17th of July 2020, the RECOVERY collaborative group has released a preliminary report discussing dexamethasone's efficacy in hospitalized COVID-19 patients [53]. They conducted an RCT enrolling 6425 patients. 2104 and 4321 patients were randomly assigned to the dexamethasone and the standard care groups, respectively. A daily dexamethasone dose of $6 \mathrm{mg}$ was administered to the treated group for up to 10 days [53].

Overall, the mortality rate was significantly lower in the dexamethasone group. However, clinical outcomes and mortality were influenced by the baseline clinical status of the patients. Stratified statistical analysis as per the patients' need for respiratory support ((1) no support vs (2) oxygen and/or mechanical ventilation) showed varied clinical outcomes among dexamethasone-treated patients [53]. A significant improvement in mortality and clinical outcomes was noted in patients already receiving respiratory support. Yet, worsened clinical outcomes and increased mortality were encountered in the dexamethasone-treated patients who initially required no respiratory support [53]. Hence, the use of dexamethasone was only endorsed in patients with severe disease requiring supplemental oxygen and ventilation support.

This randomized controlled trial conveys preliminary evidence. However, because of its large sample size and feasible design, it is considered a breakthrough study that delivers high-quality pivotal evidence. The study is limited by the lack of blinding and the advanced age of the enrolled patients. No pediatric patients were enrolled in this trial.

Congruently, Tomazini et al. reported promising outcomes. His team performed a multicenter, controlled, randomized, controlled trial involving 299 COVID-19 patients 
admitted to the intensive care unit [54]. They administered intravenous dexamethasone to 151 patients at a dose of $20 \mathrm{mg}$ once daily for 5 days, followed by a daily dose of $10 \mathrm{mg}$ until discharge. The addition of dexamethasone to standard care was linked to significantly improved respiratory outcomes and also to a reduced need for respiratory support [54]. This study has several limitations. The effect of dexamethasone on COVID-19 mortality was not assessed in this trial due to the limited follow-up duration. The trial was terminated after the favorable results of the RECOVERY trial were released. This study is also limited by its participants' advanced age and the lack of participants aged below 18 years.

In short, favorable outcomes are associated with the use of dexamethasone in patients with severe and critical COVID-19 requiring respiratory support. Nevertheless, no evidence has been derived from pediatric studies, and no pediatric patients have been included in any of the conducted adult studies. High-quality pediatric clinical trials and observational studies are needed to validate the efficacy of this medication in children with COVID-19.

\section{Ivermectin}

\section{Mechanism of action}

Ivermectin is an FDA-approved broad-spectrum antiparasitic agent applied in clinical practice since 1987 [55]. In addition to its well-known antiparasitic activity, ivermectin exhibits antineoplastic and antiviral properties [56, 57]. Its anti-viral activity against RNA viruses, such as flaviviruses, is mediated by inhibiting the nuclear localization of viral proteins. Moreover, ivermectin's activity against HIV and dengue viruses, is prompted by the inhibition of importin $\alpha / \beta$-mediated nuclear transport, a vital process in viral life cycle [58]. Ivermectin impedes the replication of DNA viruses, like pseudorabies, through the disruption of the nuclear localization of the protein UL42, a key mediator of DNA synthesis [59]. In the setting of SARS-CoV-2 infection, ivermectin seems to be an inhibitor of both viral entrance and replication. It disrupts the interaction between spike receptor binding domain and ACE2 receptor, and prevents subsequently SARS-CoV-2 cellular entry [60]. Ivermectin thwarts as well viral replication via its binding to RNA-dependent RNA polymerase (RdRp) [61].

The anti-inflammatory properties of ivermectin has been also documented. Ivermectin is a potent suppressor of the inflammatory response prompted by bacterial LPS. This anti-inflammatory effect is imparted by attenuating the production of pro-inflammatory cytokines such as TNF- $\alpha$, IL-1 $\beta$, and IL-6 [62]. Similarly, in mouse asthma model stimulated with ovalbumin, ivermectin significantly suppresses airway inflammation and hyperactivity via the inhibition of cytokines production and immune cells' recruitment [63].

\section{Pharmacology}

Ivermectin belongs to a group of 16-membered macrocytic lactone compounds called avermectins [64]. The pharmacology of ivermectin is well studied. Ivermectin is a highly fat-soluble agent with a large distribution volume of $46.9 \mathrm{~L}$. In the human body, around $93 \%$ of the ivermectin molecules are bound to plasma proteins [65]. Ivermectin's extensive binding to plasma proteins is a crucial limiter of its cellular uptake. No evidence of central nervous system penetration in humans was recorded [55]. Ivermectin displays a peak plasma level $5 \mathrm{~h}$ after an adequate oral dose, and has a halflife of $36 \mathrm{~h}$ and a clearance of $1.2 \mathrm{~L} / \mathrm{h}$ [64]. The plasma level of its metabolites is maintained for a longer time due to enterohepatic recycling [64]. Ivermectin is extensively metabolized in the liver microsomes by cytochrome P450, and is excreted mainly by feces (98\%) [64]. The usual dose used for antiparasitic purposes ranges from 150 to $200 \mu \mathrm{g} /$ $\mathrm{kg}$, but a higher dose of up to $400 \mu \mathrm{g} / \mathrm{kg}$ is used for treatment of lymphatic filariasis $[64,66]$.

\section{Clinical evidence}

Ivermectin clinical efficacy against SARS-CoV-2 has been evaluated in several small sample-sized RCTs and observational studies. A randomized, double-blinded, placebocontrolled trial was performed in Bangladesh to assess the efficacy of ivermectin alone or in combination with doxycycline on viral clearance as well as its safety. The study included 72 hospitalized individuals diagnosed by positive PCR tests. No significant difference was found among the different study arms in terms of clinical symptoms. Earlier viral clearance was noted in the ivermectin group compared to placebo, but not in the ivermectin/doxycycline combination group [67]. Another randomized double-blinded placebo-controlled study was carried out in one center in India to evaluate the efficacy of ivermectin against COVID-19. The study included 112 individuals aged 18 years and above. Patients either received $2 \mathrm{mg}$ of ivermectin on days 1 and 2 or placebo tablets. The ivermectin-treated group had significantly a higher incidence of alive discharged participants (100\%) compared to the placebo group (93\%) [68].

The ICON study is a published retrospective cohort multicenter study in South Florida that investigated the effect of ivermectin treatment on overall COVID-19 in-hospitalmortality, severe pulmonary manifestations mortality, extubation rate, and hospitalization length. The study included 280 COVID-19-confirmed patients, of which 173 received ivermectin. The study showed that ivermectin is associated with a lower overall mortality rate (15 vs. $25 \%$ ), and a lesser 
severe pulmonary manifestations associated mortality (38.8 vs $80 \%$ ). Nonetheless, there was no significant improvement in extubation rates or hospitalization length [69].

In short, evidence supporting the anti-COVID-19 activity of ivermectin is still controversial. Due to the lack of largescale randomized clinical trials, the role of ivermectin in treating COVID-19 remains to be proven. Also, studies on pediatric patients are lacking. Hence, its clinical use in pediatric population cannot be founded on the current evidence.

\section{Lopinavir/ritonavir}

\section{Mechanism of action}

Lopinavir and ritonavir are HIV-1 protease inhibitors that prevent the formation of mature and infectious HIV-1 progeny (Table 1) [70]. They are often administered in combination and merged in one pill; low-dose ritonavir is added to boost the plasma concentration of lopinavir and enhance its activity [71].

\section{Pharmacology}

The estimated half-life of a single dose of lopinavir/ritonavir is $2-3 \mathrm{~h}$. It increases to $4-6 \mathrm{~h}$ when multiple doses are administered [70]. The exact bioavailability of oral lopinavir/ritonavir is not yet known. The main component of the lopinavir/ritonavir combination is lopinavir. Due to its lipophilicity, lopinavir is highly bound to plasma protein (almost $100 \%$ ). It is metabolized by the liver CYP3A4 enzyme [70]. Ritonavir, an inhibitor of HIV protease and CYP3A4, is added to increase lopinavir's therapeutic plasma concentration. The metabolites of lopinavir/ritonavir are eliminated in the stool and not renally excreted. Cautious dosing should be applied when administering the drug to patients with hepatic impairment [70].

\section{Clinical evidence}

Given that both HIV and coronaviruses are single-stranded RNA viruses, the combination therapy of lopinavir and ritonavir was previously employed in treating patients with SARS-CoV and Middle-East-respiratory-syndrome-coronavirus (MERS-CoV) [72-74]. Similarly, the anti-SARS$\mathrm{CoV}-2$ activity of this combination was assessed in in-vitro studies. In one study, tolerable doses of lopinavir/ritonavir $(7 / 1.75 \mu \mathrm{g} / \mathrm{mL})$ were applied to Vero cells infected with SARS-CoV-2 [75]. A significant reduction in viral cytopathy and replication was noted in the lopinavir/ritonavir-treated cells compared to the non-treated cells [75]. Driven by these promising results and by the anti-SARS-CoV and -MERS$\mathrm{CoV}$ activities of lopinavir/ritonavir, several clinical trials have explored the efficacy of this combination in COVID-19 patients.

In a recent study, published on the 24th of October 2020, lopinavir/ritonavir was compared to standard supportive care in a cohort of 5040 patients. Lopinavir/ritonavir (400/100 mg) was administered, in addition to standard supportive care, to 1616 hospitalized COVID-19 patients [76]. No significant improvement in mortality rate was noted in the lopinavir-ritonavir-treated group as compared to the control group. Similarly, the rate of transition to mechanical ventilation was comparable between the two groups [76]. This study conveys the latest highest-quality evidence owing to its large sample size and appropriate design. Adequate randomization and control were applied. However, the study is subjected to a few limitations. No pediatric patients were enrolled in this study, and only a limited number of critically ill intubated patients were enrolled. Furthermore, only oral preparations of the combination therapy were available for this study. Hence, the use of these preparations was limited in patients with swallowing difficulties or gastrointestinal intolerance.

Moreover, a combination of lopinavir and ritonavir $(400 / 100 \mathrm{mg})$ was not superior to standard care in hospitalized patients with severe COVID-19. In a cohort of 199 patients, 99 patients were assigned to lopinavir/ritonavir and 100 patients to standard care [77]. There was no significant difference in the time to clinical improvement and the mortality rate between the two groups. Similarly, a few days after treatment initiation, the combination therapy was halted in $13.8 \%$ of the treated patients due to side effects [77]. Just like the previous study, this study is adequately controlled and randomized. However, it is limited by (1) the limited number of patients, (2) the lack of pediatric patients, and (3) the existence of several confounders including the difference in the baseline characteristics of the patients enrolled, and the use of concurrent medications such as dexamethasone in some patients. Both studies were not blinded and thus are subject to observer bias.

In a separate study, lopinavir/ritonavir was administered either alone or in combination with ribavirin and interferon beta- $1 \mathrm{~b}$ to hospitalized COVID-19 patients treated in several hospitals in Hong Kong, China [78]. The triple therapy, consisting of lopinavir/ritonavir, ribavirin, and interferon beta- $1 \mathrm{~b}$, was found superior to the monotherapy of lopinavir in 127 patients (86 vs 41 patients, respectively) [78]. Faster recovery and improved clinical outcomes were noted in the triple therapy group. However, no placebo or standard care control group was included in this study. Similarly, no pediatric patients were enrolled and only those with mild to moderate disease were included. Overall, based on the aforementioned evidence, we argue that a combination of lopinavir/ritonavir is ineffective in adult patients with COVID19. Similarly, this preparation has not yet been studied in 


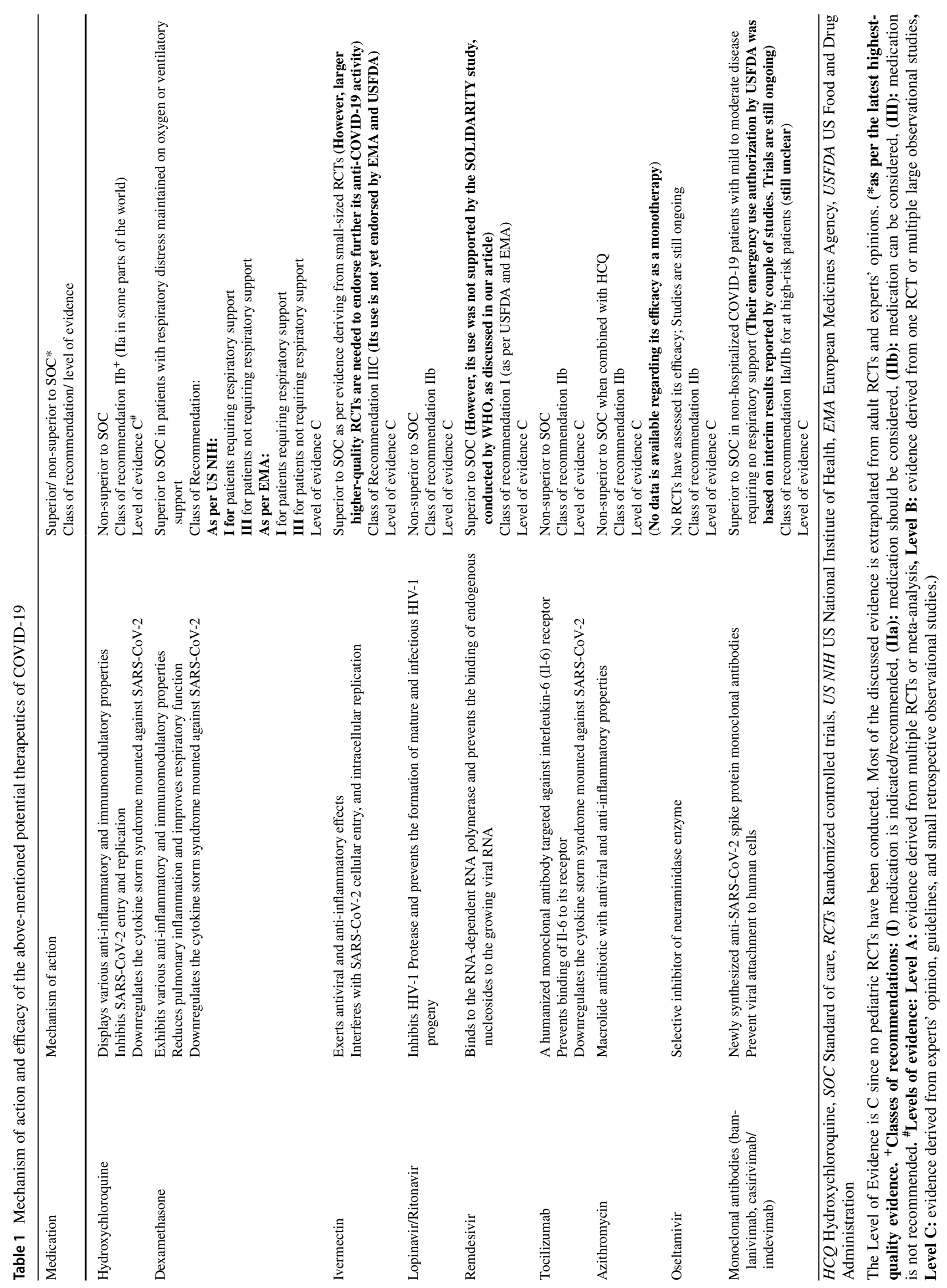


high-quality pediatric RCTs. Hence, its use in pediatric patients cannot be supported by the available evidence.

\section{Remdesivir}

\section{Mechanism of action}

Remdesivir is a novel medication employed in treating numerous RNA-based viral infections. It was initially fostered for the treatment of Ebola virus in 2014 [79, 80]. The development of remdesivir was based on previously discovered and engineered nucleoside analogs that are effective in treating RNA viruses [79-81]. Remdesivir, or GS-5734, is a monophosphoramidate adenine nucleoside analog. It binds to the RNA-dependent RNA polymerase and prevents endogenous nucleosides' binding to the growing viral RNA. Hence, it inhibits intracellular replication of RNA viruses such as Ebola, SARS-CoV, MERS-CoV, and SARS-CoV-2 [79-81]. Remdesivir is considered effective against numerous coronaviruses owing to the preserved structure of the non-structural protein 12 (nsp12) of the RNA-dependent RNA polymerase. This protein is shared by various coronaviruses and acts as a target for many antiviral medications including remdesivir [81].

Remdesivir is an inactive pro-drug that is converted by cellular enzymes into its active form: GS-443902. GS-443902 is a nucleoside triphosphate [81]. In addition to its activity against viral replication, remdesivir can escape a challenging viral mechanism imposed by coronaviruses. These viruses are recognized by their ability to express a distinctive exoribonuclease (ExoN) and thus to resist many antiviral therapeutics. The efficacy of remdesivir is partly affected by the presence of this enzyme. However, its efficacy and potency are still maintained by its ability to escape proofreading by ExoN [81].

\section{Pharmacology}

The half-life of remdesivir is estimated at $1 \mathrm{~h}$ when administered intravenously. However, the half-life of its active metabolite is around $40 \mathrm{~h}$. The oral bioavailability of remdesivir is inadequate due to its extensive first-pass metabolism. Hence, remdesivir should be administered intravenously to ensure an adequate therapeutic effect [81]. The plasma protein binding of remdesivir and its active metabolite are moderate and low, respectively. Remdesivir is believed to be metabolized by plasma hydrolases and, to a lesser extent, by hepatic enzymes. Thus, its use is contraindicated in patients with severe liver disease. The renal excretion of remdesivir is minimal; however, one of its metabolites GS-441524 is moderately excreted by the kidneys [81]. Hence, the use of remdesivir is not advised in patients with impaired renal functions and particularly in those with a glomerular filtration rate below $30 \mathrm{ml} / \mathrm{min}$. The pharmacokinetic properties of remdesivir are derived from experimental studies and adult clinical trials [81]. No studies have assessed the pharmacokinetics of remdesivir in pediatric patients.

\section{Clinical evidence}

The role of remdesivir in treating coronaviruses (i.e., SARS$\mathrm{CoV}$, MERS-CoV, and SARS-CoV-2) has been explored in numerous in vitro and in vivo animal studies [81]. Based these studies' preliminary data, remdesivir was deemed effective in treating these respiratory illnesses and preventing their pervasive propagation. Congruently, early in the course of the COVID-19 pandemic, its efficacy was assessed in a few case reports and observational studies [81]. These studies were limited by the small sample size, the limited ability to assess the moderate- and long-term efficacy and safety of remdesivir, and the lack of comparison groups. Hence, the evaluation of remdesivir in high-quality controlled randomized clinical trials was needed to endorse its safety and efficacy in COVID-19 patients.

On the 8th of October 2020, Beigel et al. released the final results of their clinical trial [82]. In this trial, they compared the efficacy of remdesivir to placebo in a cohort of 1062 patients. Five hundred and forty-one patients were treated with remdesivir over 10 days; they received a loading dose of $200 \mathrm{mg}$ on the first day, and then a 9-day course of $100 \mathrm{mg}$ [82]. As compared to the placebo group, the time to recovery was significantly shorter in the remdesivir group. A faster improvement in clinical conditions was noted in the remdesivir group [82]. Similarly, lower mortality rates were detected among the patients treated with remdesivir after 15 and 29 days of treatment initiation, respectively. The enhanced clinical improvement was statistically significant; yet, the decrease in mortality rates was not significant. More side effects were experienced by the placebo group [82]. As compared to other randomized clinical trials, this study conveys the latest highest-quality evidence [83, 84]. It has the largest number of patients and is adequately controlled and double-blinded. Patients were randomly selected from 13 countries and 60 centers. $85 \%$ of the patients had severe COVID-19 and the average age of the participants was 58.9 years. No children were enrolled in this study. Moreover, these beneficial outcomes contradict the preliminary results reported by the SOLIDARITY trial, as mentioned previously. Hence, we argue that the use of remdesivir in children cannot be based on this study. Further clinical trials, with enrolled pediatric patients, are needed to assess the efficacy and safety of remdesivir not only in adults but also in pediatric patients.

Furthermore, Goldman et al. compared the efficacy of 5-day and 10-day courses of remdesivir in a cohort of 397 patients [85]. All patients were provided with a $200 \mathrm{mg}$ 
loading dose on the first day of treatment and then with a daily dose of $100 \mathrm{mg}$ for 4 or 9 days. After 14 days of treatment initiation, comparable clinical outcomes were detected in both groups. No significant difference was noted between the two regimens of remdesivir [85]. Hence, a 5-day course of treatment can provide a favored and cost-effective approach for COVID-19 management. Nonetheless, no children were enrolled in this study, as well.

In a recently published trial, the efficacy of a combination therapy consisting of remdesivir and a Janus kinase inhibitor, baricitinib, was compared to remdesivir plus placebo in a cohort of 1033 COVID-19 hospitalized patients [86]. Superior outcomes were achieved in the combination therapy group, particularly among patients receiving high-flow oxygen or non-invasive ventilatory support. There was no significant improvement in 28-day mortality. However, fewer side effects were encountered in the combination therapy group [86]. Collectively, these findings indicate that remdesivir anti-COVID-19 efficacy may be supplemented by additional potent immunomodulators like baricitinib.

Overall, as per the above-mentioned studies, remdesivir has a good safety profile. Most of its side effects are selflimited gastrointestinal symptoms [82, 85]. Tables 2 and 3 show the adequate doses of the discussed medications and their potential side effects, respectively.

\section{Tocilizumab}

\section{Mechanism of action}

Tocilizumab is a humanized monoclonal antibody targeted against the interleukin-6 (Il-6) receptor. It competes with Il-6 and prevents its binding to its receptor. The medication was developed originally to treat rheumatoid arthritis (RA) that is refractory to conventional therapies [87]. The fostering of this medication was based on the pathologic role exerted by Il- 6 and the massive and unregulated expression and production of Il-6 in patients with autoimmune diseases such as RA and Still's disease [87, 88]. Il-6 is a pro-inflammatory cytokine secreted by numerous inflammatory cells including macrophages, B cells, and T cells among others [87]. It exerts some antiinflammatory effects as well $[87,89]$. It acts as an inhibitor of pro-inflammatory cytokines such as Il- 1 and TNF- $\alpha$ and upregulates the expression of anti-inflammatory cytokines such as Il-1 receptor antagonist and Il-10 [90]. However, in the setting of systemic autoimmune and infectious diseases, Il-6 is a crucial mediator of inflammation and tissue destruction $[88,91]$. It potentiates the B lymphocytes' activity and stimulates the differentiation of naïve T helper cells into Th2 and Th17 cells [88, 92]. Similarly, it enhances the expression of acute phase reactants such as $\mathrm{C}$-reactive protein, fibrinogen, and hepcidin. It induces the differentiation of megakaryocytes into mature platelets [88]. Hence, massive levels of Il-6 are associated with increased levels of antibodies and inflammatory molecules, as well as significant coagulopathic and thrombotic events.

\section{Pharmacology}

The elimination half-life of tocilizumab depends on the number of administered doses. An estimated half-life of $240 \mathrm{~h}$ was noted after three doses of $8 \mathrm{mg} / \mathrm{kg}$ [87]. Its volume of distribution is estimated at $6.4 \mathrm{~L}$ in patients with RA [93]. No evidence regarding its plasma protein binding and route of elimination is available. However, in one study, tocilizumab was evaluated in patients with RA and concurrent renal insufficiency. It was well-tolerated, and no significant side effects were reported [94]. Nonetheless, it was not assessed in patients with a glomerular filtration rate of less than $30 \mathrm{ml} / \mathrm{min}$. Similarly, its use is not advised in patients with acute or chronic liver diseases [95].

\section{Clinical evidence}

The addition of tocilizumab to the treatment of severe COVID-19 patients has emanated from its well-known immunomodulatory properties. Interestingly, owing to its anti-Il-6 effect, tocilizumab can alleviate the hyperinflammatory phase of COVID-19. It can downregulate the cytokine storm syndrome that often precipitates to critical and complicated COVID-19. The use of this medication in treating COVID-19 patients has been examined in multiple studies, including multicenter observational studies and randomized clinical trials.

First, Biran et al. have conducted a multicenter retrospective observational study involving ICU patients with severe COVID-19 [96]. Out of 764 patients admitted to 13 hospitals, $27 \%$ were treated with tocilizumab in addition to standard care. The clinical outcomes encountered in those treated with tocilizumab were compared to patients receiving other medical regimens. A significant improvement in clinical outcomes and mortality was noted in the tocilizumab-treated group [96]. However, the study is subjected to the inherent biases associated with observational studies, including misclassification and selection biases. No randomization and adequate control were applied. The indications for tocilizumab administration were not clearly stated. Furthermore, no pediatric patients were enrolled in this study.

Similarly, favorable outcomes were reported in numerous observational studies performed in different parts of the world [97-102]. However, contradictory unfavorable results were conveyed by higher-quality randomized clinical trials $[103$, 104]. Hermine et al. have compared the efficacy of tocilizumab 
Table 2 Adequate and proper dosing and duration of the potential therapeutics of COVID-19 [32, 33, 122, 132]

\begin{tabular}{|c|c|c|}
\hline Medication & Dose in adults & Dose in children \\
\hline Hydroxychloroquine & $\begin{array}{l}\text { A first dose of } 800 \mathrm{mg} \text { (two doses of } 400 \mathrm{mg} \text { ) on day } 1 \text {, fol- } \\
\text { lowed by a daily dose of } 400 \mathrm{mg} \text { ( } 200 \mathrm{mg} \text { twice daily) for } \\
\text { a total of } 4-7 \text { days }\end{array}$ & $\begin{array}{l}\text { Weight }<50 \mathrm{~kg} \text { : } \\
\text { A first daily dose of } 12 \mathrm{mg} / \mathrm{kg} \text { (two doses of } 6 \mathrm{mg} / \mathrm{kg}) \\
\text { on day } 1 \text { followed by a daily dose of } 6 \mathrm{mg} / \mathrm{kg}(3 \mathrm{mg} / \mathrm{kg} \\
\text { twice daily) for a total of } 4-7 \text { days } \\
\text { Weight } \geq 50 \mathrm{~kg} \text { : } \\
\text { Same as adults }\end{array}$ \\
\hline Dexamethasone & $0.15 \mathrm{mg} / \mathrm{kg}$ once daily for up to 10 days (maximal dose $6 \mathrm{mg}$ ) & \\
\hline Ivermectin & $\begin{array}{l}\text { At least one dose of } 0.2 \mathrm{mg} / \mathrm{kg} \text { (a repeat dose can be given } \\
\text { at } 7 \text { days) }\end{array}$ & $\begin{array}{l}\text { Its use in children with COVID-19 is not well studied or } \\
\text { reported }\end{array}$ \\
\hline Lopinavir/Ritonavir & $400 / 100 \mathrm{mg}$ two times per day for a total of $10-14$ days & $\begin{array}{l}\text { Age } 4 \text { days to } 1 \text { year: } \\
300 / 75 \mathrm{mg} / \mathrm{m}^{2} \text { two times per day for a total of } 7 \text { days } \\
\text { Age } 1 \text { to } 18 \text { years: } \\
12 / 3 \mathrm{mg} / \mathrm{kg} \text { two times per day for a total of } 7 \text { days }\end{array}$ \\
\hline Remdesivir & $\begin{array}{l}\text { A loading dose (LD) of } 200 \mathrm{mg} \text { followed by a daily mainte- } \\
\text { nance dose (MD) of } 100 \mathrm{mg} \text { for a total of 5-10 days }\end{array}$ & $\begin{array}{l}\text { Weight }<40 \mathrm{~kg} \text { : } \\
\text { A LD of } 5 \mathrm{mg} / \mathrm{kg} \text { followed by a daily MD of } 2.5 \mathrm{mg} / \mathrm{kg} \\
\text { Weight } \geq 40 \mathrm{~kg} \text { : } \\
\text { Same as adults }\end{array}$ \\
\hline Tocilizumab & A single dose of $8 \mathrm{mg} / \mathrm{kg}$ (maximal dose $800 \mathrm{mg}$ ) & $\begin{array}{l}\text { Weight }<30 \mathrm{~kg} \text { : } \\
\text { A single dose of } 12 \mathrm{mg} / \mathrm{kg} \\
\text { (maximal dose } 800 \mathrm{mg} \text { ) } \\
\text { Weight } \geq 30 \mathrm{~kg} \text { : } \\
\text { A single dose of } 8 \mathrm{mg} / \mathrm{kg} \\
\text { (maximal dose } 800 \mathrm{mg} \text { ) }\end{array}$ \\
\hline Azithromycin & $\begin{array}{l}\text { A first dose of } 500 \mathrm{mg} \text {, followed by a daily dose of } 250 \mathrm{mg} \\
\text { for } 4 \text { days }\end{array}$ & $\begin{array}{l}\text { A first dose of } 10 \mathrm{mg} / \mathrm{kg} \text { followed by a daily dose of } 5 \mathrm{mg} / \\
\mathrm{kg} \text { for } 4 \text { days }\end{array}$ \\
\hline Oseltamivir & $\begin{array}{l}75 \mathrm{mg} \text { twice daily for a total of } 5 \text { days } \\
\text { (N.B: The duration of treatment in immunocompromised } \\
\text { adults and children is } 10 \text { days.) }\end{array}$ & $\begin{array}{l}\text { Weight } 10-15 \mathrm{~kg} \text { : } \\
30 \mathrm{mg} \text { twice daily for a total of } 5 \text { days } \\
\text { Weight } 15-23 \mathrm{~kg} \text { : } \\
45 \mathrm{mg} \text { twice daily for a total of } 5 \text { days } \\
\text { Weight } 24-40 \mathrm{~kg} \text { : } \\
60 \mathrm{mg} \text { twice daily for a total of } 5 \text { days } \\
\text { Weight } \geq 40 \mathrm{~kg} \text { : } \\
\text { Same as adults }\end{array}$ \\
\hline
\end{tabular}

to usual care in a cohort of adult hospitalized patients with moderate to severe disease [103]. One hundred and thirty-one patients were enrolled in this RCT, and almost half the patients were treated with tocilizumab. No significant improvement in clinical outcomes or mortality rate was achieved by the addition of tocilizumab to usual care [103]. In a second RCT, Salvarani et al. have assessed the efficacy of tocilizumab and standard care in preventing disease progression in a cohort of 126 COVID-19 hospitalized patients with pneumonia [104]. Around $50 \%$ of the patients were randomly assigned to the tocilizumab group. No added benefit was associated with the use of tocilizumab in these patients [104]. Only adult patients were included in these two studies, and no ICU patients were enrolled in any of these studies. Similarly, both studies were limited by the small number of enrolled patients. Hence, larger RCTs involving patients from different age groups and with distinct stages of COVID-19 are needed to adequately assess the role of tocilizumab in reducing the economic, medical, and social burdens of COVID-19.

\section{Others: azithromycin, oseltamivir, monoclonal antibodies, vitamins and minerals}

\section{Azithromycin}

Azithromycin is a macrolide antibiotic used in the treatment of numerous bacterial illnesses including communityacquired bacterial pneumonia. It covers a broad spectrum of bacteria and is effective against numerous Gram-negative, Gram-positive, and atypical bacteria [105]. It exerts its antibacterial effect by binding to bacterial ribosome and inhibition mRNA translation and protein synthesis. It is a bacteriostatic antibiotic that leads to thwarted bacterial growth [105]. Similarly, azithromycin is known to exert antiviral and antiparasitic properties. It has been used in treating parasitic illnesses such as babesiosis, malaria, and toxoplasmosis, and viral infections such as MERS-CoV, respiratory syncytial virus, SARS-CoV-1, and lately SARS-CoV-2 [106-112]. Its anti-SARS-CoV-2 effects are mediated by azithromycin's 
Table 3 Safety profile of the above-mentioned potential therapeutics of COVID-19 [32, 33, 83, 103, 122, 132-140]

\begin{tabular}{|c|c|c|c|}
\hline Medication & Potential side effects & Cautions & Contraindications \\
\hline Hydroxychloroquine & $\begin{array}{l}\text { Diarrhea, elevated liver enzymes, nau- } \\
\text { sea, vomiting, myopathy, headache, } \\
\text { retinopathy, cardiac arrhythmias (AV } \\
\text { block, QT interval prolongation... } \\
\text { etc.) }\end{array}$ & $\begin{array}{l}\text { Severe renal or liver diseases } \\
\text { Severe GI, CNS or hematologic } \\
\text { diseases } \\
\text { G6PD deficiency } \\
\text { Arrhythmias }\end{array}$ & $\begin{array}{l}\text { Hypersensitivity } \\
\text { Preexisting retinopathy } \\
\text { Pregnancy }\end{array}$ \\
\hline Dexamethasone & Hypertension, Hyperglycemia & $\begin{array}{l}\text { CKD } \\
\text { Diabetes mellitus } \\
\text { GI ulcers } \\
\text { Heart failure } \\
\text { Hypertension }\end{array}$ & $\begin{array}{l}\text { Hypersensitivity } \\
\text { Fungemia } \\
\text { Avoid live and live-attenuated vaccines }\end{array}$ \\
\hline Ivermectin & $\begin{array}{l}\text { Gastrointestinal side effects, hypoten- } \\
\text { sion, cutaneous rashes, neurotoxic } \\
\text { symptoms (confusion, seizure, and } \\
\text { lightheadedness) }\end{array}$ & Moderate to severe hepatic dysfunction & Hypersensitivity \\
\hline Lopinavir/Ritonavir & $\begin{array}{l}\text { Diarrhea, elevated liver enzymes, } \\
\text { nausea, vomiting, cardiac arrhythmia } \\
\text { (prolonged PR/QT interval) }\end{array}$ & $\begin{array}{l}\text { Mild to moderate hepatic dysfunction } \\
\text { Dyslipidemia } \\
\text { Diabetes mellitus }\end{array}$ & $\begin{array}{l}\text { Hypersensitivity } \\
\text { Severe hepatic dysfunction }\end{array}$ \\
\hline Remdesivir & $\begin{array}{l}\text { Constipation, diarrhea, nausea, vomit- } \\
\text { ing, elevated liver enzymes, hypoten- } \\
\text { sion, anemia, thrombocytopenia, } \\
\text { hyperglycemia, hypersensitivity }\end{array}$ & $\begin{array}{l}\text { Mild to moderate hepatic and renal } \\
\text { dysfunction }\end{array}$ & $\begin{array}{l}\text { Hypersensitivity } \\
\text { Stage } 4-5 \text { CKD } \\
\text { Severe hepatic dysfunction }\end{array}$ \\
\hline Tocilizumab & $\begin{array}{l}\text { Gastrointestinal side effects, hepatitis, } \\
\text { neutropenia, lymphopenia, anemia, } \\
\text { hypersensitivity }\end{array}$ & $\begin{array}{l}\text { Untreated latent tuberculosis (TB) } \\
\text { Chronic Hepatitis B infection } \\
\text { Active/Chronic liver disease } \\
\text { Hematologic disease } \\
\text { Avoid live and live-attenuated vaccines }\end{array}$ & $\begin{array}{l}\text { Hypersensitivity } \\
\text { Pregnancy } \\
\text { Breastfeeding } \\
\text { Active TB/ systemic fungal infections }\end{array}$ \\
\hline Azithromycin & $\begin{array}{l}\text { Gastrointestinal side effects, headache, } \\
\text { skin rashes, cardiac arrythmias (QT } \\
\text { interval prolongation, bradycardia) }\end{array}$ & $\begin{array}{l}\text { Severe hepatic or renal disease } \\
\text { Cardiac arrhythmias }\end{array}$ & Hypersensitivity \\
\hline Oseltamivir & $\begin{array}{l}\text { Gastrointestinal side effects, cough, } \\
\text { nasal congestion, fatigue, dizziness, } \\
\text { insomnia, headache, hypersensitivity }\end{array}$ & $\begin{array}{l}\text { Stage } 4 / 5 \text { CKD (GFR of less than } \\
30 \mathrm{ml} / \mathrm{min} \text { ) } \\
\text { Severe hepatic impairment }\end{array}$ & Hypersensitivity \\
\hline
\end{tabular}

activity against viral entry and pro-inflammatory cytokines' release [113]. Hence, it exerts both antiviral and anti-inflammatory effects (see Fig. 2).

To date, no RCT has endorsed the use of azithromycin in treating COVID-19 patients. This medication's off-label use is founded on its above-mentioned antiviral properties and on evidence deriving from previous coronavirus outbreaks and low-quality observational studies [42-44]. However, as per data reported by two multicenter RCTs, a combination of HCQ and azithromycin is ineffective in treating and preventing COVID-19 progression [114, 115]. Nonetheless, only adult patients were enrolled in these studies. Furthermore, no trials have studied the efficacy of monotherapy azithromycin in treating COVID-19. A few large multicenter randomized controlled trials tackling this use are still ongoing $[116,117]$.

\section{Oseltamivir}

Oseltamivir is an anti-influenza A and B medication used in patients aged 1 year and above. It acts as a selective inhibitor of the influenza virus's neuraminidase enzymes that are essential for viral entry, internalization, replication, and progeny release [118-121]. The drug is administered orally at a dose of $75 \mathrm{mg}$ twice daily in adults and children more than 13 years and weighing more than $40 \mathrm{~kg}$. In younger patients, the dosage varies depending on the weight of the patient [122]. The dosage of oseltamivir should be adjusted in patients with a GFR of less than $30 \mathrm{ml} / \mathrm{min}$. However, oseltamivir's use is not recommended in patients with a GFR below $10 \mathrm{ml} / \mathrm{min}$ [118]. There is no indication for dosage adjustment in patients with mild to moderate hepatic impairment. Oseltamivir is known to exhibit a low profile of drug-drug interactions [118]. Hence, it can be safely administered to a wide spectrum of patients including children and adults with mild-moderate hepatic and renal impairments.

No RCT has examined the efficacy of oseltamivir in treating adult or pediatric COVID-19 patients. Nonetheless, its off-label use has been documented in these patients. Indeed, in a large multicenter cohort study, including 582 pediatric patients from 25 European 
countries, oseltamivir was the fourth most-used medication following hydroxychloroquine, remdesivir, and lopinavir-ritonavir, respectively [39]. This use is based on the antiviral properties of the medication and on experience with former coronaviruses. For instance, in a retrospective study involving pediatric patients with non-SARS-CoV-2 coronaviruses treated at 15 European countries between 2016 and 2018, a faster recovery was associated with the use of oseltamivir [123]. Extensive multicenter studies are needed to recommend the off-label use of this medication in pediatric COVID-19 patients.

\section{Monoclonal antibodies: bamlanivimab, casirivimab/ imdevimab}

On the 9th of November 2020, the USFDA has authorized bamlanivimab in adult and pediatric non-hospitalized COVID-19 patients with mild to moderate symptoms [124]. Bamlanivimab, or LY-CoV555, is a novel monoclonal antibody targeted against the spike protein of SARS-CoV-2. It hinders viral attachment to human cells and impedes its entry and replication within these cells [125]. This medication is authorized only in patients aged 12 years and above, and weighing at least $40 \mathrm{~kg}$. Bamlanivimab's use is advised in at high-risk patients age more than 65 years or having at least one of the following comorbidities: obesity $\left(\mathrm{BMI} \geq 35 \mathrm{~kg} / \mathrm{m}^{2}\right)$, chronic kidney disease, diabetes, and immunosuppressive diseases. It is also indicated in patients with respiratory and cardiovascular diseases who are aged 55 years and above [126]. As for pediatric patients, its use is recommended in all at high-risk children aged at least 12 years. Children with cardiac, respiratory, neurodegenerative, and sickle cell diseases as well as obese children with a BMI of $85^{\text {th }}$ percentile and above are candidates for bamlanivimab [126]. Nonetheless, adult and pediatric patients requiring oxygen or respiratory support should not receive this medication [125].
Bamlanivimab's USFDA emergency use authorization (EUA) is based on preliminary results reported to the USFDA by a couple of ongoing studies [125]. Serious safety concerns have been associated with the administration of bamlanivimab to hospitalized patients. Hence, studies exploring bamlanivimab's use in this population has been suspended a week before the EUA's release [125]. However, reduced rates of hospitalization and progression to severe disease have been associated with the addition of this medication to the supportive standard of care (SOC) of non-hospitalized patients [125].

Similarly, on November 21, the emergency use of a novel preparation consisting of two monoclonal antibodies, casirivimab/imdevimab (or REGN-CoV2), has been authorized by the USFDA in non-hospitalized COVID-19 patients aged 12 years and above and at high-risk for progression to severe and complicated disease (see Fig. 3) [127, 128]. Just like bamlanivimab, these antibodies are directed against the spike protein of SARS-CoV-2. They inhibit viral entry and thus replication. As per the interim results of a single clinical trial, the addition of REGN-CoV2 to SOC is associated with hampered progression of COVID-19 and diminished rates of hospitalization [129]. Nonetheless, this preparation is contraindicated in patients with respiratory distress requiring oxygen or ventilation support, and also in all hospitalized patients [129].

To note, an EUA permits the use of an unapproved medication in particular populations and supports its evaluation in clinical trials. This authorization is not equivalent to a USFDA approval of a relatively well-studied medication. An EUA is only followed by official approval if the medication is deemed effective in clinical trials.

\section{Vitamins and minerals}

Dietary supplements, such as vitamins $\mathrm{C}, \mathrm{D}$, and zinc, have gained increased attention over the last year. They are regarded as potential immune boosters that may induce

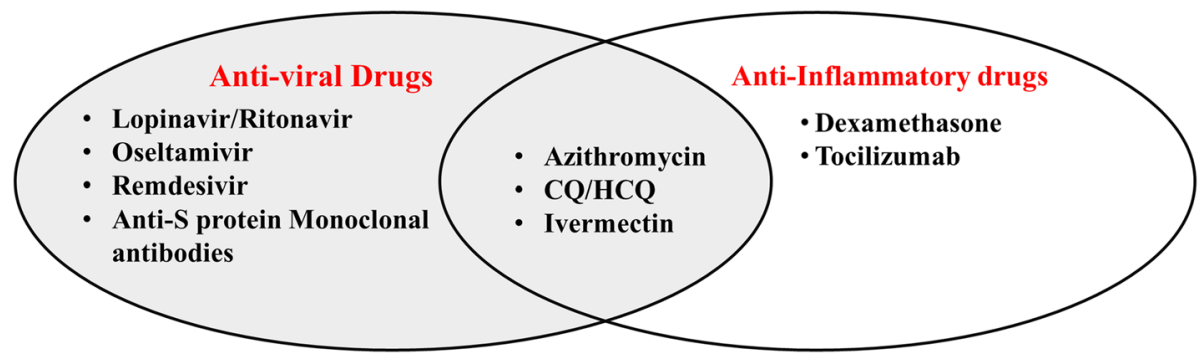

Fig. 2 The distribution of the discussed COVID-19 therapeutics as per their main mechanism of action. Lopinavir/ritonavir, oseltamivir, remdesivir, and anti-SARS-CoV-2 spike (S) protein monoclonal antibodies are anti-viral drugs with distinct SARS-CoV-2 inhibitory effects. Azithromycin, chloroquine/hydroxychloroquine, and ivermectin display both antiviral and anti-inflammatory properties. Dexamethasone and tocilizumab display no direct antiviral properties; however, they exert anti-inflammatory effects that contribute in attenuating excessive pro-inflammatory responses 
therapeutic and prophylactic anti-COVID-19 properties. The use of these supplements is based on their well-known nutritional and immunomodulatory properties [19]. However, high-quality randomized controlled trials are needed to evaluate these supplements' role and recommend their use in treating and preventing COVID-19.

\section{The levels of the reported evidence and the classes of the suggested recommendations}

The evidence mentioned above is drawn from multicenter adult RCTs and international guidelines suggested by pediatric specialists. However, no pediatric patients, aged 18 years and less, have been enrolled in any of these studies. Subsequently, we postulate that the current evidence deduced from non-pediatric studies and applied to pediatric population is low-quality level $\mathrm{C}$ evidence (Table 1). As for adults, we suggest that most of the available evidence, inferred from numerous multicenter RCTs, is considered high-quality level A evidence. Consequently, we suggest that further pediatric studies are urgently needed to determine the most efficacious anti-SARS-CoV-2 medication that can be safely administered to these patients.

Regarding the classes of the suggested recommendations, we classified the medications as per the class of recommendation (Table 1). Indicated/recommended medications are considered class I recommendations. Medications that should or may be considered are class IIa and IIb recommendations, respectively. Unrecommended medications are considered class III recommendations. According to the USFDA, remdesivir is indicated/recommended in hospitalized children aged 12 years and above, and weighing at least $40 \mathrm{~kg}$. Additionally, the USFDA has authorized the emergency use of bamlanivimab and casirivimab/imdevimab to non-hospitalized COVID-19 patients aged 12 years and above and weighing at least $40 \mathrm{~kg}$ who are at high-risk for complicated disease. As mentioned previously, these monoclonal antibodies are only recommended in non-hospitalized patients requiring no respiratory support, since it may prevent the progression from mild and moderate to severe and critical COVID-19 [127]. Other medications, such as hydroxychloroquine, azithromycin, tocilizumab, and ivermectin among others (see Table 1), can be occasionally considered in non-remdesivir candidates. Furthermore, as per EMA, both remdesivir and dexamethasone are recommended [130].

Based on the information displayed above, we suggest the adoption of the treatment algorithm depicted in Fig. 4. Supportive care, consisting of fluids supplementation and antipyretics, should be offered to all patients regardless of the disease severity. Dexamethasone is indicated in patients with respiratory distress necessitating oxygen or ventilation support. Remdesivir should be provided to all eligible candidates requiring respiratory support. If remdesivir is contraindicated, tocilizumab may be added to treat patients with severe and complicated COVID-19 entailing excessive release of pro-inflammatory cytokines. In short, the addition of tocilizumab to the medical regimen is favored particularly in pediatric patients with MIS-C. These patients should likely receive antiplatelet medications such as aspirin and anticoagulant medications such as enoxaparin that can prevent the occurrence of life-threatening thromboembolic events. The USFDA-authorized monoclonal antibodies are indicated in non-hospitalized patients at high risk for disease progression, as indicated previously.

\section{Conclusion}

In sum, no RCTs have included pediatric patients, to date. The bulk of the current evidence is derived and extrapolated from adult-targeted studies. Of the aforementioned medications, remdesivir is the only USFDA-approved medication in hospitalized patients. In November 2020, the USFDA has permitted the use of novel monoclonal antibodies, bamlanivimab and casirivimab/imdevimab, in non-hospitalized at-risk COVID-19 patients with mild to moderate disease necessitating no respiratory support. However, the efficacy of these preparations should be validated by high-quality clinical trials. Furthermore, only remdesivir and dexamethasone were proven to be effective in multicenter placebo-controlled RCTs, unlike the remaining medications.
Fig. 3 Indications for antiSARS-CoV-2 spike protein monoclonal antibodies in children $[126,128]$
Children Eligible For Anti-S protein Monoclonal Antibodies (Bamlanivimab, Casirivimab/Imdevimab)

Non-hospitalized SARS-CoV-2-positive children aged $\geq 12$ years and weighing $\geq 40 \mathrm{~kg}$ and having at least one of the following comorbidities:

1. Sickle cell disease

2. Cardiac disease (ex. Congenital Heart Disease)

3. Chronic pulmonary disease (ex. Asthma)

4. CNS disorders (ex. Cerebral Palsy) 
Nonetheless, dexamethasone is recommended by both the US National Institute of Health (NIH) and the EMA only for patients requiring respiratory support. Subsequently, its use is only endorsed in adult and pediatric COVID-19 patients maintained on oxygen therapy or mechanical ventilation. Even with all the exerted efforts and the accomplished achievements, further high-quality RCTs involving pediatric patients are urgently needed to attain top evidence and provide the highest-quality care to these patients.

Finally, vaccination remains the ultimate prevention method that may control the spread of COVID-19 and reduce its fatality. Interestingly, numerous vaccine candidates are currently studied in pre-clinical and clinical trials [131]. Nonetheless, the development of an effective anti-SARS$\mathrm{CoV}-2$ vaccine is hampered by several challenges reflected primarily by the novelty of SARS-CoV-2, the scarcity of sufficient time, and the ambiguity of the immune response mounted against SARS-CoV-2. Hence, further clinical trials are likely needed to expedite the development of these vaccines.

\section{Take home messages}

- Little is known about the treatment of pediatric COVID19 patients.

- The bulk of the available evidence is obtained from adult studies.

- Supportive measures directed toward controlling body temperature, preventing dehydration, and maintaining adequate oxygenation are the mainstay of COVID-19 treatment.

- Remdesivir is indicated exclusively in hospitalized patients who are aged 12 years and above.

- Dexamethasone is recommended in patients requiring respiratory support. It improves mortality in those receiving oxygen or ventilatory support.

Author contributions MA and AHE conceived of the idea of the review. MA, FB, and AHE developed the review framework. NKY and $\mathrm{ROZ}$ wrote the first draft of the manuscript. All authors contributed to

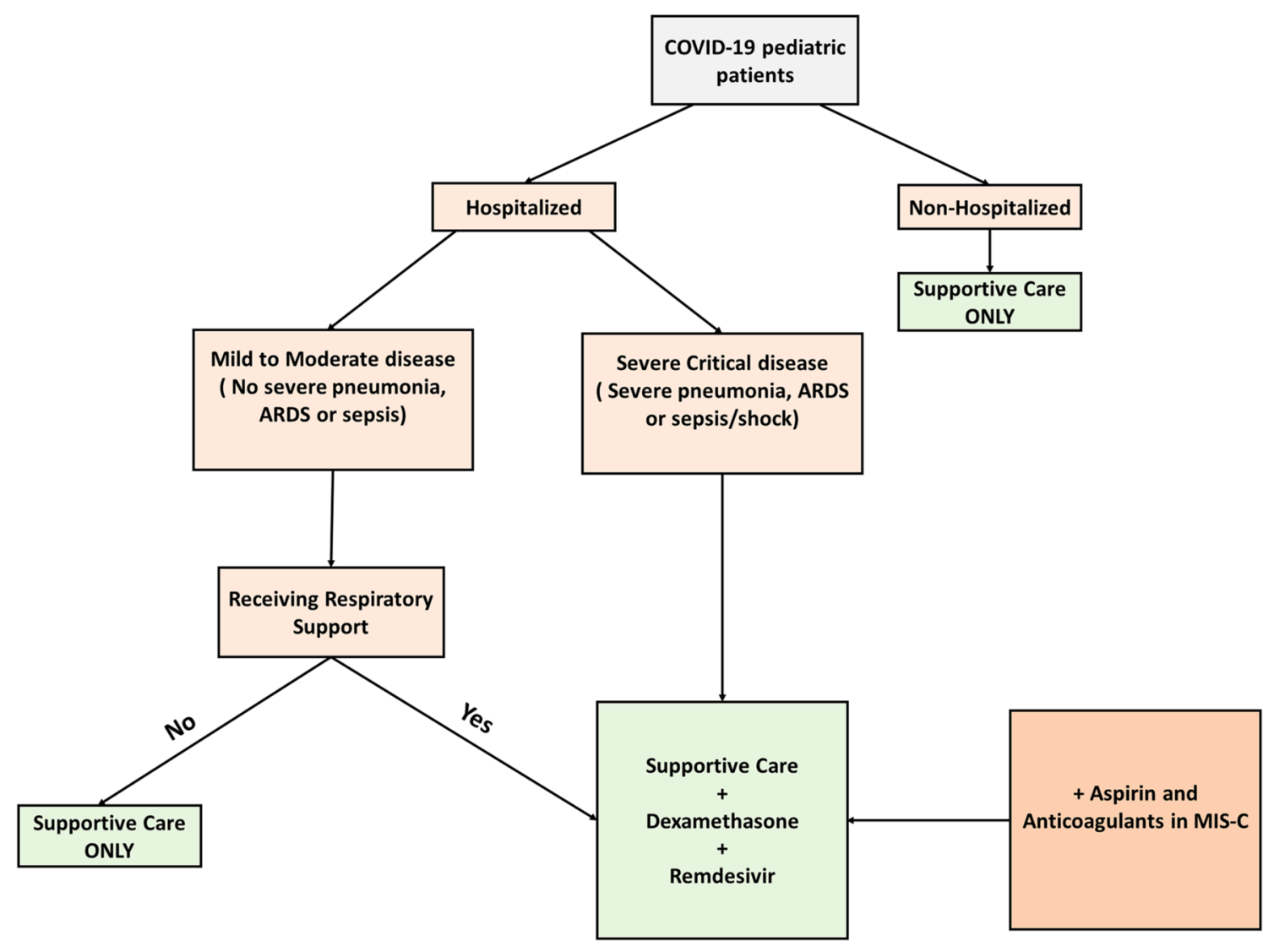

Fig. 4 Suggested treatment algorithm. Supportive care consisting of fluids replacement and fever reduction should be offered to all COVID-19 pediatric patients regardless of hospitalization status and disease severity. Patients requiring respiratory support (oxygen or mechanical ventilation) should receive dexamethasone and remdesivir in addition to supportive care. Aspirin and anticoagulants should be add to the treatment of children with multisystem inflammatory syndrome. If remdesivir is contraindicated, other immunomodulators, such as IVIG and tocilizumab, may be considered in children with MIS as well. ARDS Acute respiratory distress syndrome, $M I S-C$ multisystem inflammatory syndrome in children 
corrections and adjustment of subsequent iterations of the manuscript. All authors approve and agree with the content.

Funding Open access funding provided by the Qatar National Library.

\section{Declarations}

Conflict of interest The authors declare no conflict of interest.

Open Access This article is licensed under a Creative Commons Attribution 4.0 International License, which permits use, sharing, adaptation, distribution and reproduction in any medium or format, as long as you give appropriate credit to the original author(s) and the source, provide a link to the Creative Commons licence, and indicate if changes were made. The images or other third party material in this article are included in the article's Creative Commons licence, unless indicated otherwise in a credit line to the material. If material is not included in the article's Creative Commons licence and your intended use is not permitted by statutory regulation or exceeds the permitted use, you will need to obtain permission directly from the copyright holder. To view a copy of this licence, visit http://creativecommons.org/licenses/by/4.0/.

\section{References}

1. Wang C, Horby PW, Hayden FG, Gao GF. A novel coronavirus outbreak of global health concern. Lancet. 2020;395:470-3.

2. Ding Q, Lu P, Fan Y, Xia Y, Liu M. The clinical characteristics of pneumonia patients coinfected with 2019 novel coronavirus and influenza virus in Wuhan, China. J Med Virol. 2020;92(9):1549-55.

3. Zhu N, Zhang D, Wang W, Li X, Yang B, Song J, et al. A Novel coronavirus from patients with pneumonia in China, 2019. N Engl J Med. 2020;382:727-33.

4. Younis NK, Zareef RO, Mohammad Ali NM, Maktabi R. The era of the coronavirus disease 2019 pandemic: a review on dynamics, clinical symptoms and complications, diagnosis, and treatment. Genetic Testing Molecular Biomarkers. 2021;25:85-101.

5. Younis NK, Rahm M, Bitar F, Arabi M. COVID-19 in the MENA region: facts and findings. J Infect Dev Ctries. 2021;15:342-9.

6. Chauhan S. Comprehensive review of coronavirus disease 2019 (COVID-19). Biomed J. 2020;43:334-40.

7. Ortiz-Prado E, Simbana-Rivera K, Gomez-Barreno L, RubioNeira M, Guaman LP, Kyriakidis NC, et al. Clinical, molecular, and epidemiological characterization of the SARS-CoV-2 virus and the Coronavirus Disease 2019 (COVID-19), a comprehensive literature review. Diagn Microbiol Infect Dis. 2020;98:115094.

8. WHO. WHO Coronavirus Disease (COVID-19) Dashboard; 2020.

9. Naghipour S, Ghodousi M, Rahsepar S, Elyasi S. Repurposing of well-known medications as antivirals: hydroxychloroquine and chloroquine-from HIV-1 infection to COVID-19. Expert Rev Anti-infective Ther. 2020;18(11):1119-33.

10. Pawar AY. Combating devastating COVID-19 by drug repurposing. Int J Antimicrob Agents. 2020;56:105984.

11. Sanders JM, Monogue ML, Jodlowski TZ, Cutrell JB. Pharmacologic treatments for coronavirus disease 2019 (COVID-19): a review. JAMA. 2020;323:1824-36.

12. Ali MJ, Hanif M, Haider MA, Ahmed MU, Sundas F, Hirani A, et al. Treatment options for COVID-19: a review. Front Med (Lausanne). 2020;7:480

13. Akhtar B, Muhammad F, Sharif A, Hannan A. Therapeutic options for treatment of COVID-19: a review from repur-posed drugs to new drug targets. Curr Drug Targets. 2020. https://doi. org/10.2174/1389450121999201006193329.

14. Singh TU, Parida S, Lingaraju MC, Kesavan M, Kumar D, Singh RK. Drug repurposing approach to fight COVID-19. Pharmacol Rep. 2020;72(6):1479-508.

15. Selvi V. Convalescent plasma: a challenging tool to treat COVID19 patients-a lesson from the past and new perspectives. Biomed Res Int. 2020;2020:2606058.

16. Liu STH, Lin HM, Baine I, Wajnberg A, Gumprecht JP, Rahman F, et al. Convalescent plasma treatment of severe COVID-19: a propensity score-matched control study. Nat Med. 2020. https:// doi.org/10.1038/s41591-020-1088-9.

17. Shen C, Wang Z, Zhao F, Yang Y, Li J, Yuan J, et al. Treatment of 5 critically ill patients with COVID-19 with convalescent plasma. JAMA. 2020;323:1582-9.

18. Valk SJ, Piechotta V, Chai KL, Doree C, Monsef I, Wood EM, et al. Convalescent plasma or hyperimmune immunoglobulin for people with COVID-19: a rapid review. Cochrane Database Syst Rev. 2020;5:013600.

19. Shakoor H, Feehan J, Al Dhaheri AS, Ali HI, Platat C, Ismail LC, et al. Immune-boosting role of vitamins D, C, E, zinc, selenium and omega-3 fatty acids: could they help against COVID-19? Maturitas. 2020. https://doi.org/10.1016/j.maturitas.2020.08.003.

20. Michienzi SM, Badowski ME. Can vitamins and/or supplements provide hope against coronavirus? Drugs Context. 2020. https:// doi.org/10.7573/dic.2020-5-7.

21. Ali N. Role of vitamin D in preventing of COVID-19 infection, progression and severity. J Infect Public Health. 2020;13:1373-80.

22. U.S. Food and Drug Administration. COVID-19 Update: FDA Broadens Emergency Use Authorization for Veklury (remdesivir) to Include All Hospitalized Patients for Treatment of COVID-19; 2020.

23. U.S. Food and Drug Administration. FDA Approves First Treatment for COVID-19; 2020.

24. Ciuca IM. COVID-19 in children: an ample review. Risk Manag Healthc Policy. 2020;13:661-9.

25. Ludvigsson JF. Systematic review of COVID-19 in children shows milder cases and a better prognosis than adults. Acta Paediatr. 2020;109:1088-95.

26. Zareef RO, Younis NK, Bitar F, Eid AH, Arabi M. COVID-19 in pediatric patients: a focus on CHD patients. Front Cardiovasc Med. 2020. https://doi.org/10.3389/fcvm.2020.612460.

27. Schvartz A, Belot A, Kone-Paut I. Pediatric inflammatory multisystem syndrome and rheumatic diseases during SARS-CoV-2 pandemic. Front Pediatrics. 2020;8:605807.

28. Haslak F, Yıldız M, Adrovic A, Şahin S, Barut K, Kasapçopur Ö. A recently explored aspect of the iceberg named COVID-19: multisystem inflammatory syndrome in children (MIS-C). Turkish Arch Pediatrics. 2021;56:3-9.

29. Haşlak F, Yıldız M, Adrovic A, Barut K, Kasapçopur Ö. Childhood rheumatic diseases and COVID-19 pandemic: an intriguing linkage and a New Horizon. Balkan Med J. 2020;37:184-8.

30. Wati DK, Manggala AK. Overview of management of children with COVID-19. Clin Exp Pediatr. 2020;63:345-54.

31. Chiotos K, Hayes M, Kimberlin DW, Jones SB, James SH, Pinninti SG, et al. Multicenter initial guidance on use of antivirals for children with coronavirus disease 2019/severe acute respiratory syndrome coronavirus 2. J Pediatric Infect Dis Soc. 2020;9(6):701-15.

32. Venturini E, Montagnani C, Garazzino S, Dona D, Pierantoni L, Lo Vecchio A, et al. Treatment of children with COVID-19: position paper of the Italian Society of Pediatric Infectious Disease. Ital J Pediatr. 2020;46:139.

33. Children's Hospital of the King's Daughters. CHKD Treatment Guideline for COVID-19 in Children; 2020. 
34. Teich VD, Klajner S, Almeida FAS, Dantas ACB, Laselva $\mathrm{CR}$, Torritesi MG, et al. Epidemiologic and clinical features of patients with COVID-19 in Brazil. Einstein (Sao Paulo). 2020;18:eA06022.

35. Schwartz RA, Suskind RM. Azithromycin and COVID-19: prompt early use at first signs of this infection in adults and children an approach worthy of consideration. Dermatol Ther. 2020;33:13785.

36. Younis NK, Zareef RO, Al Hassan SN, Bitar F, Eid AH, Arabi M. Hydroxychloroquine in COVID-19 patients: pros and cons. Front Pharmacol. 2020. https://doi.org/10.3389/fphar.2020.597985.

37. Furst DE. Pharmacokinetics of hydroxychloroquine and chloroquine during treatment of rheumatic diseases. Lupus. 1996;5(Suppl 1):S11-5.

38. Avdic, E. Hydroxychloroquine Johns Hopkins ABX Guide; 2020.

39. Götzinger F, Santiago-García B, Noguera-Julián A, Lanaspa M, Lancella L, Carducci FIC, et al. COVID-19 in children and adolescents in Europe: a multinational, multicentre cohort study. Lancet Child \& Adolesc Health. 2020;4:653-61.

40. WHO. "Solidarity" clinical trial for COVID-19 treatments; 2020.

41. Horby P, Mafham M, Linsell L, Bell JL, Staplin N, Emberson JR, et al. Effect of hydroxychloroquine in hospitalized patients with COVID-19. N Engl J Med. 2020. https://doi.org/10.1056/ NEJMoa2022926.

42. Million M, Lagier JC, Gautret P, Colson P, Fournier PE, Amrane S, et al. Early treatment of COVID-19 patients with hydroxychloroquine and azithromycin: a retrospective analysis of 1061 cases in Marseille, France. Travel Med Infect Dis. 2020;35:101738.

43. Gautret P, Lagier JC, Parola P, Hoang VT, Meddeb L, Sevestre $\mathrm{J}$, et al. Clinical and microbiological effect of a combination of hydroxychloroquine and azithromycin in 80 COVID-19 patients with at least a six-day follow up: a pilot observational study. Travel Med Infect Dis. 2020;34:101663.

44. Gautret P, Lagier J-C, Parola P, Meddeb L, Mailhe M, Doudier $\mathrm{B}$, et al. Hydroxychloroquine and azithromycin as a treatment of COVID-19: results of an open-label non-randomized clinical trial. International J Antimicrob Agents. 2020;56(1):105949.

45. Yu B, Li C, Chen P, Zhou N, Wang L, Li J, Jiang H, Wang D-W. Low dose of hydroxychloroquine reduces fatality of critically ill patients with COVID-19. Sci China Life Sci. 2020;63(1):1515-21.

46. McKay L, Cidlowski J. Physiologic and pharmacologic effects of corticosteroids. In: Holland-Frei Cancer Medicine. DC Becker; 2003. p. 6.

47. El Azab SR, Rosseel PM, de Lange JJ, Groeneveld AB, van Strik $\mathrm{R}$, van Wijk EM, et al. Dexamethasone decreases the pro- to antiinflammatory cytokine ratio during cardiac surgery. Br J Anaesth. 2002;88:496-501.

48. Mogensen TH, Berg RS, Paludan SR, Ostergaard L. Mechanisms of dexamethasone-mediated inhibition of Toll-like receptor signaling induced by Neisseria meningitidis and Streptococcus pneumoniae. Infect Immun. 2008;76:189-97.

49. Ziesche E, Scheiermann P, Bachmann M, Sadik CD, Hofstetter C, Zwissler B, et al. Dexamethasone suppresses interleukin-22 associated with bacterial infection in vitro and in vivo. Clin Exp Immunol. 2009; 157:370-6.

50. Donohue JF, Ohar JA. Effects of corticosteroids on lung function in asthma and chronic obstructive pulmonary disease. Proc Am Thorac Soc. 2004;1:152-60.

51. Czock D, Keller F, Rasche FM, Haussler U. Pharmacokinetics and pharmacodynamics of systemically administered glucocorticoids. Clin Pharmacokinet. 2005;44:61-98.

52. Spoorenberg SM, Deneer VH, Grutters JC, Pulles AE, Voorn GP, Rijkers GT, et al. Pharmacokinetics of oral vs. intravenous dexamethasone in patients hospitalized with community-acquired pneumonia. Br J Clin Pharmacol. 2014;78:78-83.
53. Group RC, Horby P, Lim WS, Emberson JR, Mafham M, Bell $\mathrm{JL}$, et al. Dexamethasone in hospitalized patients with Covid19-preliminary report. N Engl J Med. 2020;43(3):183.

54. Tomazini BM, Maia IS, Cavalcanti AB, Berwanger O, Rosa $\mathrm{RG}$, Veiga VC, et al. Effect of dexamethasone on days alive and ventilator-free in patients with moderate or severe acute respiratory distress syndrome and COVID-19: The CoDEX randomized clinical trial. JAMA. 2020;324:1307-16.

55. Canga AG, Prieto AMS, Liébana MJD, Martínez NF, Vega MS, Vieitez JJG. The pharmacokinetics and interactions of ivermectin in humans-a mini-review. AAPS J. 2008;10:42-6.

56. Tang M, Hu X, Wang Y, Yao X, Zhang W, Yu C, et al. Ivermectin, a potential anticancer drug derived from an antiparasitic drug. Pharmacol Res. 2020;163:105207.

57. Wehbe Z, Wehbe M, Iratni R, Pintus G, Zaraket H, Yassine HM, et al. Repurposing ivermectin for COVID-19: molecular aspects and therapeutic possibilities. Front Immunol. 2021. https://doi. org/10.3389/fimmu.2021.663586.

58. Wagstaff KM, Sivakumaran H, Heaton SM, Harrich D, Jans DA. Ivermectin is a specific inhibitor of importin $\alpha / \beta$-mediated nuclear import able to inhibit replication of HIV-1 and dengue virus. Biochemical J. 2012;443:851-6.

59. Lv C, Liu W, Wang B, Dang R, Qiu L, Ren J, et al. Ivermectin inhibits DNA polymerase UL42 of pseudorabies virus entrance into the nucleus and proliferation of the virus in vitro and vivo. Antiviral Res. 2018;159:55-62.

60. Lehrer S, Rheinstein PH. Ivermectin docks to the SARS-CoV-2 spike receptor-binding domain attached to ACE2. In Vivo. 2020;34:3023-6.

61. Sen Gupta PS, Biswal S, Panda SK, Ray AK, Rana MK. Binding mechanism and structural insights into the identified protein target of COVID-19 and importin- $\alpha$ with in-vitro effective drug ivermectin. J Biomol Struct Dyn. 2020 https://doi.org/10.1080/ 07391102.2020 .1839564

62. Zhang X, Song Y, Ci X, An N, Ju Y, Li H, et al. Ivermectin inhibits LPS-induced production of inflammatory cytokines and improves LPS-induced survival in mice. Inflamm Res. 2008;57:524-9.

63. Yan S, Ci X, Chen N, Chen C, Li X, Chu X, et al. Anti-inflammatory effects of ivermectin in mouse model of allergic asthma. Inflamm Res. 2011;60:589-96.

64. Chhaiya SB, Mehta DS, Kataria BC. Ivermectin: pharmacology and therapeutic applications. Int J Basic Clin Pharmacol. 2012;1:132-9.

65. Audus K, Knaub S, Guillot F, Schaeffer J. The effect of protein binding on ivermectin uptake by bovine brain microvessel endothelial cells. Vet Res Commun. 1992;16:365-77.

66. Ottesen E, Ramachandran C. Lymphatic filariasis infection and disease: control strategies. Elsevier Current Trends; 1995.

67. Ahmed S, Karim MM, Ross AG, Hossain MS, Clemens JD, Sumiya MK, et al. A five-day course of ivermectin for the treatment of COVID-19 may reduce the duration of illness. Int J Infect Dis. 2020;103:214-6.

68. Roy R, Pattadar C, Raj R, Agarwal N, Biswas B, Majhi PK, et al. Ivermectin as a potential treatment for mild to moderate COVID-19-A double blind randomized placebo-controlled trial. medRxiv. 2021.

69. Rajter JC, Sherman MS, Fatteh N, Vogel F, Sacks J, Rajter J-J. ICON (Ivermectin in COvid Nineteen) Study: use of ivermectin is associated with lower mortality in hospitalized patients with COVID-19. Available at SSRN 3631261. 2020.

70. Chandwani A, Shuter J. Lopinavir/ritonavir in the treatment of HIV-1 infection: a review. Ther Clin Risk Manag. 2008;4:1023-33.

71. Cvetkovic RS, Goa KL. Lopinavir/ritonavir: a review of its use in the management of HIV infection. Drugs. 2003;63:769-802. 
72. Zhong H, Wang Y, Zhang ZL, Liu YX, Le KJ, Cui M, et al. Efficacy and safety of current therapeutic options for COVID19-lessons to be learnt from SARS and MERS epidemic: a systematic review and meta-analysis. Pharmacol Res. 2020;157:104872.

73. Chu CM, Cheng VC, Hung IF, Wong MM, Chan KH, Chan KS, et al. Role of lopinavir/ritonavir in the treatment of SARS: initial virological and clinical findings. Thorax. 2004;59:252-6.

74. Chan JF, Yao Y, Yeung ML, Deng W, Bao L, Jia L, et al. Treatment With lopinavir/ritonavir or interferon-betalb improves outcome of MERS-CoV infection in a nonhuman primate model of common marmoset. J Infect Dis. 2015;212:1904-13.

75. Kang CK, Seong MW, Choi SJ, Kim TS, Choe PG, Song SH, et al. In vitro activity of lopinavir/ritonavir and hydroxychloroquine against severe acute respiratory syndrome coronavirus 2 at concentrations achievable by usual doses. Korean J Intern Med. 2020;35:782-7.

76. Group RC. Lopinavir-ritonavir in patients admitted to hospital with COVID-19 (RECOVERY): a randomised, controlled, open-label, platform trial. Lancet. 2020. https://doi.org/10. 1016/S0140-6736(20)32013-4.

77. Cao B, Wang Y, Wen D, Liu W, Wang J, Fan G, et al. A trial of lopinavir-ritonavir in adults hospitalized with severe Covid-19. N Engl J Med. 2020;382:1787-99.

78. Hung IF, Lung KC, Tso EY, Liu R, Chung TW, Chu MY, et al. Triple combination of interferon beta-1b, lopinavir-ritonavir, and ribavirin in the treatment of patients admitted to hospital with COVID-19: an open-label, randomised, phase 2 trial. Lancet. 2020;395:1695-704.

79. Eastman RT, Roth JS, Brimacombe KR, Simeonov A, Shen M, Patnaik S, et al. Remdesivir: a review of its discovery and development leading to emergency use authorization for treatment of COVID-19. ACS Cent Sci. 2020. https://doi.org/10. 1021/acscentsci.0c00489.

80. Pardo J, Shukla AM, Chamarthi G, Gupte A. The journey of remdesivir: from Ebola to COVID-19. Drugs Context. 2020. https://doi.org/10.7573/dic.2020-4-14.

81. Jorgensen SCJ, Kebriaei R, Dresser LD. Remdesivir: review of pharmacology, pre-clinical data, and emerging clinical experience for COVID-19. Pharmacotherapy. 2020;40:659-71.

82. Beigel JH, Tomashek KM, Dodd LE, Mehta AK, Zingman BS, Kalil AC, et al. Remdesivir for the treatment of Covid19-final report. N Engl J Med. 2020. https://doi.org/10.1056/ NEJMoa2007764.

83. Wang Y, Zhang D, Du G, Du R, Zhao J, Jin Y, et al. Remdesivir in adults with severe COVID-19: a randomised, double-blind, placebo-controlled, multicentre trial. Lancet. 2020;395:1569-78.

84. Spinner CD, Gottlieb RL, Criner GJ, Arribas Lopez JR, Cattelan AM, Soriano Viladomiu A, et al. Effect of remdesivir vs standard care on clinical status at 11 days in patients with moderate COVID-19: a randomized clinical trial. JAMA. 2020;324:1048-57.

85. Goldman JD, Lye DCB, Hui DS, Marks KM, Bruno R, Montejano R, et al. Remdesivir for 5 or 10 days in patients with severe covid-19. N Engl J Med. 2020. https://doi.org/10.1056/NEJMo a2015301.

86. Kalil AC, Patterson TF, Mehta AK, Tomashek KM, Wolfe CR, Ghazaryan V, et al. Baricitinib plus remdesivir for hospitalized adults with Covid-19. N Engl J Med. 2020. https://doi.org/10. 1056/NEJMoa2031994.

87. Sebba A. Tocilizumab: the first interleukin-6-receptor inhibitor. Am J Health Syst Pharm. 2008;65:1413-8.

88. Tanaka T, Narazaki M, Kishimoto T. IL-6 in inflammation, immunity, and disease. Cold Spring Harb Perspect Biol. 2014;6:a016295.
89. Scheller J, Chalaris A, Schmidt-Arras D, Rose-John S. The proand anti-inflammatory properties of the cytokine interleukin-6. Biochim Biophys Acta. 2011;1813:878-88.

90. Pedersen BK, Steensberg A, Schjerling P. Muscle-derived interleukin-6: possible biological effects. J Physiol. 2001;536:329-37.

91. Gabay C. Interleukin-6 and chronic inflammation. Arthritis Res Ther. 2006;8(Suppl 2):S3.

92. Dienz O, Rincon M. The effects of IL-6 on CD4 T cell responses. Clin Immunol. 2009;130:27-33.

93. Tutuncu Z, Kavanaugh A. Anti-cytokine Therapies - Kelley and Firestein's Textbook of Rheumatology Tenth Edition; 2017.

94. Mori S, Yoshitama T, Hidaka T, Hirakata N, Ueki Y. Effectiveness and safety of tocilizumab therapy for patients with rheumatoid arthritis and renal insufficiency: a real-life registry study in Japan (the ACTRA-RI study). Ann Rheum Dis. 2015;74:627-30.

95. Dzintars K. Tocilizumab. Johns Hopkins ABX Guide; 2020.

96. Biran N, Ip A, Ahn J, Go RC, Wang S, Mathura S, et al. Tocilizumab among patients with COVID-19 in the intensive care unit: a multicentre observational study. Lancet Rheumatol. 2020;2:e603-12.

97. Xu X, Han M, Li T, Sun W, Wang D, Fu B, et al. Effective treatment of severe COVID-19 patients with tocilizumab. Proc Natl Acad Sci U S A. 2020;117:10970-5.

98. Toniati P, Piva S, Cattalini M, Garrafa E, Regola F, Castelli F, et al. Tocilizumab for the treatment of severe COVID-19 pneumonia with hyperinflammatory syndrome and acute respiratory failure: a single center study of 100 patients in Brescia, Italy. Autoimmun Rev. 2020;19:102568.

99. Price CC, Altice FL, Shyr Y, Koff A, Pischel L, Goshua G, et al. Tocilizumab treatment for cytokine release syndrome in hospitalized patients with coronavirus disease 2019: survival and clinical outcomes. Chest. 2020;158:1397-408.

100. Guaraldi G, Meschiari M, Cozzi-Lepri A, Milic J, Tonelli $\mathrm{R}$, Menozzi $\mathrm{M}$, et al. Tocilizumab in patients with severe COVID-19: a retrospective cohort study. Lancet Rheumatol. 2020;2:e474-84.

101. Sciascia S, Aprà F, Baffa A, Baldovino S, Boaro D, Boero R, et al. Pilot prospective open, single-arm multicentre study on off-label use of tocilizumab in severe patients with COVID-19. Clin Exp Rheumatol. 2020;38:529-32.

102. Dastan F, Saffaei A, Haseli S, Marjani M, Moniri A, Abtahian $\mathrm{Z}$, et al. Promising effects of tocilizumab in COVID-19: a noncontrolled, prospective clinical trial. Int Immunopharmacol. 2020;88:106869.

103. Hermine O, Mariette X, Tharaux PL, Resche-Rigon M, Porcher R, Ravaud P, et al. Effect of tocilizumab vs usual care in adults hospitalized with COVID-19 and moderate or severe pneumonia: a randomized clinical trial. JAMA Intern Med. 2020;181(1):32-40.

104. Salvarani C, Dolci G, Massari M, Merlo DF, Cavuto S, Savoldi $\mathrm{L}$, et al. Effect of tocilizumab vs standard care on clinical worsening in patients hospitalized with COVID-19 pneumonia: a randomized clinical trial. JAMA Intern Med. 2020;181(1):24-31.

105. Jelic D, Antolovic R. From erythromycin to azithromycin and new potential ribosome-binding antimicrobials. Antibiotics (Basel). 2016;5(3):29.

106. Arabi YM, Deeb AM, Al-Hameed F, Mandourah Y, Almekhlafi GA, Sindi AA, et al. Macrolides in critically ill patients with Middle East Respiratory Syndrome. Int J Infect Dis. 2019;81:184-90.

107. Kong M, Zhang WW, Sewell K, Gorman G, Kuo HC, Aban I, et al. Azithromycin treatment vs placebo in children with respiratory syncytial virus-induced respiratory failure: a phase 2 randomized clinical trial. JAMA Netw Open. 2020;3:e203482.

108. Oliver ME, Hinks TSC. Azithromycin in viral infections. Rev Med Virol. 2020;31(2):e2163. 
109. Pani A, Lauriola M, Romandini A, Scaglione F. Macrolides and viral infections: focus on azithromycin in COVID-19 pathology. Int J Antimicrob Agents. 2020;56:106053.

110. Taylor WR, Richie TL, Fryauff DJ, Ohrt C, Picarima H, Tang $\mathrm{D}$, et al. Tolerability of azithromycin as malaria prophylaxis in adults in Northeast Papua, Indonesia. Antimicrob Agents Chemother. 2003. https://doi.org/10.1128/AAC.47.7.21992203.2003.

111. Lashay A, Mirshahi A, Parandin N, Riazi Esfahani H, Mazloumi M, Reza Lashay M, et al. A prospective randomized trial of azithromycin versus trimethoprim/sulfamethoxazole in treatment of toxoplasmic retinochoroiditis. J Curr Ophthalmol. 2017;29:120-5.

112. Krause PJ, Lepore T, Sikand VK, Gadbaw J Jr, Burke G, Telford SR 3rd, et al. Atovaquone and azithromycin for the treatment of babesiosis. N Engl J Med. 2000;343:1454-8.

113. Kaddoura M, AlIbrahim M, Hijazi G, Soudani N, Audi A, Alkalamouni H, et al. COVID-19 therapeutic options under investigation. Front Pharmacol. 2020;11:1196.

114. Cavalcanti AB, Zampieri FG, Rosa RG, Azevedo LCP, Veiga VC, Avezum A, et al. Hydroxychloroquine with or without azithromycin in mild-to-moderate Covid-19. N Engl J Med. 2020. https://doi.org/10.1056/NEJMx200021.

115. Furtado RHM, Berwanger O, Fonseca HA, Correa TD, Ferraz LR, Lapa MG, et al. Azithromycin in addition to standard of care versus standard of care alone in the treatment of patients admitted to the hospital with severe COVID-19 in Brazil (COALITION II): a randomised clinical trial. Lancet. 2020;396:959-67.

116. Hinks TSC, Barber VS, Black J, Dutton SJ, Jabeen M, Melhorn $\mathrm{J}$, et al. A multi-centre open-label two-arm randomised superiority clinical trial of azithromycin versus usual care in ambulatory COVID-19: study protocol for the ATOMIC2 trial. Trials. 2020;21:718

117. ClinicalTrials.gov. Azithromycin in Hospitalized COVID-19 Patients (AIC); 2020.

118. Davies BE. Pharmacokinetics of oseltamivir: an oral antiviral for the treatment and prophylaxis of influenza in diverse populations. J Antimicrob Chemother. 2010;65(Suppl 2):ii5-10.

119. Benton DJ, Wharton SA, Martin SR, McCauley JW. Role of neuraminidase in influenza A(H7N9) virus receptor binding. J Virol. 2017. https://doi.org/10.1056/NEJMx200021.

120. Matrosovich MN, Matrosovich TY, Gray T, Roberts NA, Klenk HD. Neuraminidase is important for the initiation of influenza virus infection in human airway epithelium. J Virol. 2004;78:12665-7.
121. McAuley JL, Gilbertson BP, Trifkovic S, Brown LE, McKimmBreschkin JL. Influenza virus neuraminidase structure and functions. Front Microbiol. 2019;10:39.

122. EMC. Tamiflu 75 mg Hard Capsules. 2020.

123. Coenen S, van Der Velden AW, Cianci D, Goossens H, Bongard E, Saville BR, et al. Oseltamivir for coronavirus illness: posthoc exploratory analysis of an open-label, pragmatic, randomised controlled trial in European primary care from 2016 to 2018 . Br J Gen Pract. 2020;70:e444-9.

124. U.S Food and Drug Administration. Coronavirus (COVID-19) Update: FDA Authorizes Monoclonal Antibody for Treatment of COVID-19. FDA; 2020

125 Mahase E. Covid-19: FDA authorises neutralising antibody bamlanivimab for non-admitted patients. BMJ. 2020;371:m4362.

126. U.S. Food and Drug Administration. FACT SHEET FOR HEALTH CARE PROVIDERS EMERGENCY USE AUTHORIZATION (EUA) OF BAMLANIVIMAB. FDA; 2020.

127. U.S. Food and Drug Administration. Coronavirus (COVID-19) Update: FDA Authorizes Monoclonal Antibodies for Treatment of COVID-19. U.S. Food and Drug Administration; 2020.

128. U.S. Food and Drug Administration. Fact sheet for health care providers emergency use authorization (EUA) of casirivimab and imdevimab. FDA; 2020

129. Mahase E. Covid-19: RECOVERY trial will evaluate "antiviral antibody cocktail.” BMJ. 2020;370:m3584.

130. EMA. Treatments and vaccines for COVID-19. European Medicines Agency; 2020.

131. Jeyanathan M, Afkhami S, Smaill F, Miller MS, Lichty BD, Xing Z. Immunological considerations for COVID-19 vaccine strategies. Nat Rev Immunol. 2020;20:615-32.

132. Schwartz RA, Suskind RM. Azithromycin and COVID-19: Prompt early use at first signs of this infection in adults and children, an approach worthy of consideration. Dermatol Ther. 2020;33:e13785.

133. NIH. COVID-19 treatment guidelines. 2020.

134. EMC. Remdesivir datapharm. 2020.

135. EMC. Tocilizumab datapharm. 2020.

136. EMC. Dexamethasone datapharm. 2020.

137. EMC. Lopinavir/Ritonavir datapharm. 2020.

138. EMC. Hydroxychloroquine sulfate datapharm. 2020.

139. EMC. Azithromycin datapharm. 2020.

140. Administration USFaD. FAQ: COVID-19 and ivermectin intended for animals. 2020. 